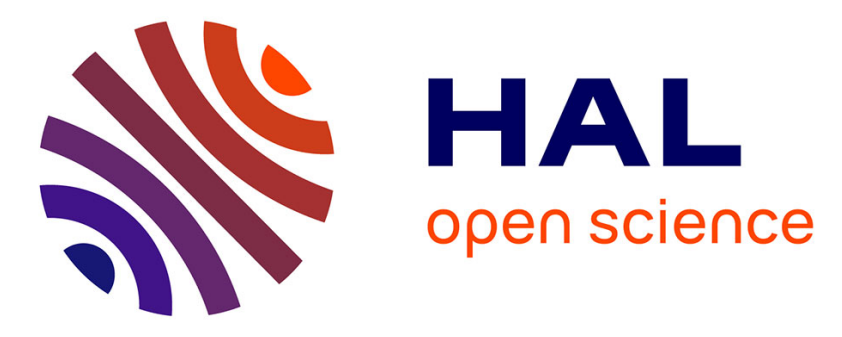

\title{
Comprehensive analysis of alternative downscaled soil moisture products
}

Sabah Sabaghy, Jeffrey P. Walker, Luigi J. Renzullo, Ruzbeh Akbar, Steven

Chan, Julian Chaubell, Narendra Das, R. Scott Dunbar, Dara Entekhabi, Anouk Gevaert, et al.

\section{To cite this version:}

Sabah Sabaghy, Jeffrey P. Walker, Luigi J. Renzullo, Ruzbeh Akbar, Steven Chan, et al.. Comprehensive analysis of alternative downscaled soil moisture products. Remote Sensing of Environment, 2020, 239, pp.111586. 10.1016/j.rse.2019.111586 . hal-03035074

\section{HAL Id: hal-03035074 https://hal.science/hal-03035074}

Submitted on 2 Dec 2020

HAL is a multi-disciplinary open access archive for the deposit and dissemination of scientific research documents, whether they are published or not. The documents may come from teaching and research institutions in France or abroad, or from public or private research centers.
L'archive ouverte pluridisciplinaire HAL, est destinée au dépôt et à la diffusion de documents scientifiques de niveau recherche, publiés ou non, émanant des établissements d'enseignement et de recherche français ou étrangers, des laboratoires publics ou privés. 


\section{Comprehensive analysis of alternative downscaled}

\section{soil moisture products}

Sabah Sabaghy ${ }^{* 1}$, Jeffrey P. Walker ${ }^{1}$, Luigi J. Renzullo², Ruzbeh Akbar ${ }^{5}$, Steven

Chan $^{3}$, Julian Chaubell ${ }^{3}$, Narendra Das $^{3}$, R. Scott Dunbar ${ }^{3}$, Dara Entekhabi ${ }^{5}$, Anouk

Gevaert $^{4}$, Thomas J. Jackson ${ }^{6}$, Alexander Loew ${ }^{11}$, Olivier Merlin ${ }^{7}$, Mahta

Moghaddam $^{8}$, Jian Peng ${ }^{11,12,13}$, Jinzheng Peng ${ }^{9,10}$, Jeffrey Piepmeier ${ }^{9}$, Christoph

Rüdiger ${ }^{1}$, Vivien Stefan ${ }^{7}$, Xiaoling $\mathrm{Wu}^{1}$, Nan $\mathrm{Ye}^{1}$, and Simon $\mathrm{Yueh}^{3}$

${ }^{1}$ Department of Civil Engineering, Monash University, VIC 3800, Australia.

${ }^{2}$ Fenner School of Environment and Society, The Australian National University, Canberra, Australia.

${ }^{3}$ Jet Propulsion Laboratory, California Institute of Technology, Pasadena, CA 91109 USA.

${ }^{4}$ Earth and Climate Cluster, Department of Earth Sciences, VU Amsterdam, Amsterdam, The Netherlands.

${ }^{5}$ Department of Civil and Environmental Engineering, Massachusetts Institute of Technology, Cambridge, MA 02139 USA.

${ }^{6}$ U.S. Department of Agriculture ARS, Hydrology and Remote Sensing Laboratory, Beltsville, MD 20705 USA.

${ }^{7}$ Centre d'Etudes Spatiales de la Biosphère (CESBIO), 18 Avenue, Edouard Belin, bpi 2801, Toulouse 31401, France.

${ }^{8}$ Department of Electrical Engineering, University of Southern California, Los Angeles, CA 90089 USA.

${ }^{9}$ Goddard Space Flight Center, 8800 Greenbelt Rd, Greenbelt, MD 20771, USA.

${ }^{10}$ Universities Space Research Association, Columbia, MD, USA.

${ }^{11}$ Department of Geography, University of Munich (LMU), 80333 Munich, Germany.

${ }^{12}$ School of Geography and the Environment, University of Oxford, OX1 3QY Oxford, UK.

${ }^{13}$ Max Planck Institute for Meteorology, 20146 Hamburg, Germany. 
Journal: Remote Sensing of Environment

*sabah.sabaghy@monash.edu 
This is a PDF file of the pre-print version of the manuscript that has been published in the Journal Remote Sensing of Environment.

Please cite this article as: Sabah Sabaghy, Jeffrey P. Walker, Luigi J. Renzullo, Ruzbeh Akbar, Steven Chan, Julian Chaubell, Narendra Das, R. Scott Dunbar, Dara Entekhabi, Anouk Gevaert, Thomas J. Jackson, Alexander Loew, Olivier Merlin, Mahta Moghaddam, Jian Peng, Jinzheng Peng, Jeffrey Piepmeier, Christoph Rüdiger, Vivien Stefan, Xiaoling Wu, Nan Ye, Simon Yueh, Comprehensive analysis of alternative downscaled soil moisture products, Remote Sensing of Environment, Volume 239, 2020, 111586, ISSN 0034-4257.

https://doi.org/10.1016/j.rse.2019.111586.

http://www.sciencedirect.com/science/article/pii/S0034425719306066 


\section{Abstract}

Recent advances in L-band passive microwave remote sensing provide an unprecedented opportunity to monitor soil moisture at $\sim 40 \mathrm{~km}$ spatial resolution around the globe. Nevertheless, retrieval of the accurate high spatial resolution soil moisture maps that are required to satisfy hydro-meteorological and agricultural applications remains a challenge. Currently, a variety of downscaling, otherwise known as disaggregation, techniques have been proposed as the solution to disaggregate the coarse passive microwave soil moisture into high-to-medium resolutions. These techniques take advantage of the strengths of both the passive microwave observations of soil moisture having low spatial resolution and the spatially detailed information on land surface features that either influence or represent soil moisture variability. However, such techniques have typically been developed and tested individually under differing weather and climate conditions, meaning that there is no clear guidance on which technique performs the best. Consequently, this paper presents a quantitative assessment of the existing radar-, optical-, radiometer-, and oversampling-based downscaling techniques using a singular extensive data set collected specifically for that purpose, being the Soil Moisture Active Passive Experiment (SMAPEx)-4 and -5 airborne field campaigns, and the OzNet in situ stations, to determine the relative strengths and weaknesses of their performances. The oversampling-based soil moisture product best captured the temporal and spatial variability of the reference soil moisture overall, though the radar-based products had a better temporal agreement with airborne soil moisture during the short SMAPEx-4 period. Moreover, the difference between temporal analysis of products against in situ and airborne soil moisture reference data sets pointed to the fact that relying on in situ measurements alone is not appropriate for validation of spatially enhanced soil moisture maps.

Keywords: Downscaling, Disaggregation, Inter-comparison, High resolution, Soil moisture, SMAP, SMOS, SMAPEX 


\section{Introduction}

Soil moisture influences land-atmosphere interaction via fluxes of energy and water, and thus impacts weather and climate conditions (Seneviratne et al., 2010), hydrology (Corradini, 2014; Koster et al., 2004, 2010) and agricultural production (Bolten et al., 2010). The ability to provide reliable, spatially distributed and temporally consistent measurements of soil moisture will therefore be of great benefit. Key to providing such information economically across the globe has been the development of L-band passive microwave remote sensing technology (Entekhabi et al., 2010; Kerr et al., 2016). The passive L-band microwave approach is widely accepted as the optimum technology for soil moisture estimation (Entekhabi et al., 2010).

There are currently two L-band passive microwave satellite missions dedicated to monitoring the near surface soil moisture every 2 to 3 days: i) the European Space Agency (ESA) Soil Moisture and Ocean Salinity (SMOS), launched in November 2009 as the first ever dedicated satellite for soil moisture mapping, and ii) the National Aeronautics and Space Administration (NASA) Soil Moisture Active Passive (SMAP), launched in January 2015 as the first ever satellite to combine a radar and radiometer to produce an enhanced resolution soil moisture product. Together, the SMOS and SMAP missions have provided a continuity of dedicated satellite soil moisture observations globally since 2010 (Kerr et al., 2016).

Soil moisture estimates at the native resolution of both the SMOS and SMAP radiometers are at a coarse scale of approximately $40 \mathrm{~km}$ (but provided on $25 \mathrm{~km}$ and $36 \mathrm{~km}$ grid spacing, respectively), which is not sufficient to meet the spatial resolution requirements of hydro-meteorological, agricultural and carbon cycle applications (e.g. Entekhabi et al., 2010; Molero et al., 2016). However, the inclusion of an L-band radar on SMAP was to provide spatial scale improvement of the radiometric observations by combining with the L-band radiometer observations (Entekhabi et al., 2010; O'Neill et al., 2010). The sensitivity of radar backscatter to soil moisture dynamics and the geophysical properties of the soil surface was expected to 
contribute to improvement of the retrievals' accuracy and disaggregation of radiometric soil moisture estimates (Chauhan, 1997; Petropoulos et al., 2015). However, loss of coincident radar imaging in July 2015, due to a hardware anomaly, meant that an alternative downscaling approach had to be sought. Moreover, there is no radar sensor aboard SMOS. Consequently, alternative downscaling techniques have been applied to the two soil moisture missions, with the aim to accurately and efficiently increase the resolution of SMOS and SMAP passive L-band soil moisture (and/or brightness temperature).

Reviews of techniques for downscaling passive microwave data for high resolution soil moisture mapping have been recently published by Sabaghy et al. (2018) and Peng et al. (2017). Downscaling methods exploit both the accuracy of the passive L-band microwave observations and the high resolution spatial variability of the ancillary data. Accordingly, downscaling techniques include, but are not limited to radar-, optical-, radiometer-, and oversampling-based methods.

The radar-based downscaling techniques (Akbar and Moghaddam, 2015; Bindlish et al., 2008; Das et al., 2011, 2014; Piles et al., 2009; Zhan et al., 2006) are based on radar-radiometer combination algorithms which enhance the spatial detail of coarse radiometric soil moisture using the spatially varied information on land surface features provided by radar. The extent of correlation between backscatter and soil moisture, and sensitivity of backscatter to soil moisture changes determine the success of radar-based downscaling techniques in estimating the variation of soil moisture in space (Wu et al., 2014).

The basic concept behind the optical-based downscaling techniques (e.g. Fang et al., 2013; Merlin et al., 2006, 2008a,b, 2012, 2013; Piles et al., 2011, 2012, 2013) is the feature space between vegetation index and surface temperature in the shape of a triangle/trapezoid (e.g. Carlson et al., 1994; Gillies and Carlson, 1995) which indicates wet and dry conditions at its edges. This feature space adjusts the sensitivity of land surface temperature to soil moisture as a function of vegetation cover density and canopy type. 
The radiometer-based downscaling technique (e.g. Gevaert et al., 2015; Santi, 2010) uses radiometric emissions at higher frequency (Ka-band, 26 to $40 \mathrm{GHz}$ ) to provide information about spatial variability of the surface when there is no rainfall event (Gevaert et al., 2015). The advantage of the radiometer- (over the optical-) based approach lies in the capacity of radiometer imagery to deliver ancillary data under all-weather conditions and being less affected by the soil surface condition. However, the radiometer-based technique is not able to improve the resolution of soil moisture content to the same extent as the optical-based techniques due to the coarser resolution of that data, as the resolution of downscaled products is dictated by that of the ancillary data used for the downscaling.

The oversampling-based method (Chan et al., 2018; Chaubell, 2016) applies an interpolation technique which rescales the brightness temperature values to $30 \mathrm{~km}$ and posted onto a $9 \mathrm{~km}$ grid. Consequently, it creates the most optimal brightness temperature by aggregating brightness temperature values that are centred near a particular radius with a relatively short length of intervals. For the methods that downscale the brightness temperature (e.g. oversampling- and radiometer-based techniques), soil moisture retrieval is then conducted on the higher resolution brightness temperature using the same passive microwave soil moisture retrieval algorithm as for the coarse observations.

A diversity of downscaling approaches exist, typically developed and tested under differing weather and climate conditions. However, until now there has been no rigorous test to assess which downscaling methodology yields the best overall soil moisture estimation at higher resolution over a specific location and climate condition, which can only be achieved by comparing the approaches on a common data set. Therefore, this paper presents a comprehensive inter-comparison of the various downscaling techniques against each other and reference data to determine the relative strengths and weaknesses of their performance. This is the first comprehensive assessment of the complete range of different radar-, optical-, radiometer-, and oversampling-based downscaled soil moisture products which are readily available using the 
same set of evaluation data, in order to take a step towards multi-sensor high resolution soil moisture retrieval for typical Australian landscapes. The performance of downscaled products was also benchmarked against the radiometer-only retrievals of SMAP and SMOS.

This paper has focused on analysing the performance of downscaled soil moisture products for a typical Australian landscape and climate. However, deep insight into the performance of downscaled soil moisture products requires similar inter-comparisons be undertaken for different climate conditions and landscapes around the world. Consequently, the curators of such data sets (eg. Soil Moisture Active Passive Validation EXperiment (SMAPVEX)) are encouraged to conduct similar soil moisture inter-comparisons over their sites.

\section{Study area and reference data sets}

The Yanco agricultural area in New South Wales, Australia, was chosen to conduct this research. Yanco has a lansdscape and climate that is representative of much of southeast Australia. The climate is classified as semi-arid based on the Köppen-Geiger climate classification system. An average annual amount of about $400 \mathrm{~mm}$ precipitation falls in the Yanco area throughout the year, and its' minimum and maximum average annual temperature is equal to $11^{\circ} \mathrm{C}$ and $24^{\circ} \mathrm{C}$, respectively (Bureau of Meterology, 2018). The Yanco area is located on a flat plain in the Murrumbidgee River catchment and contains a network of soil moisture and rainfall monitoring stations as part of OzNet (Smith et al., 2012). The locations of OzNet stations installed in the Yanco region are shown as black dots in Figure 1. Moreover, the soil moisture measurements utilized for evaluation in this study are those over the $0-5 \mathrm{~cm}$ depth of soil, which is widely accepted as being the monitoring depth of L-band passive microwave soil moisture and their downscaled soil moisture products. These data are available from http://www.oznet.org. au. The temporal pattern of soil moisture is consistent with the occurrence of precipitation events with wetting and drying cycles for the 1st April to 1st November 2015 study period as shown in Figure 2. The study area is relatively flat, with a variety of land use, soil and vegetation types, 
thus making Yanco an appropriate site for evaluation of downscaling algorithm performance.

Over the Yanco region, the Soil Moisture Active Passive Experiment (SMAPEx)-4 and -5 airborne campaigns were designed to cover an area of about $71 \mathrm{~km} \times 89 \mathrm{~km}\left(145.98^{\circ}-146.75^{\circ} \mathrm{E}\right.$ longitude and $34.22^{\circ}-35.03^{\circ} \mathrm{S}$ latitude, see Figure 1) for the purpose of calibration and validation of SMAP soil moisture products. These experiments were carried out during the Australian autumn (SMAPEx-4, from the 1st to 22nd May 2015 when crops were in the early growth stage or under cultivation) and spring (SMAPEx-5, from 7th to 27th September 2015 when crops were in the maturity stage). During SMAPEx-4 and -5 airborne field campaigns, airborne Lband passive microwave brightness temperature were collected using the Polarimetric L-band Multi-beam Radiometer (PLMR) instrument concurrent with the SMAP and SMOS satellite overpasses. The PLMR radiometer, having similar characteristics to that of the SMAP and SMOS missions, provided brightness temperature at both vertical and horizontal polarization with $1 \mathrm{~km}$ resolution, and thus soil moisture for an equivalent depth to that from SMAP and SMOS. It collected dual-polarized brightness temperature measurements with six-beams at across-track incidence angles of $\pm 7^{\circ}, \pm 21.5^{\circ}$, and $\pm 38.5^{\circ}$, which were then angle normalized to $\pm 38.5^{\circ}$ using the approach of Ye et al. (2015) before retrieval of the soil moisture. These airborne observations were supported by ground sampling activities that were conducted concurrent to flight acquisitions, to provide information about vegetation (biomass, vegetation water content, leaf area index, etc.) and surface roughness, which were used for the soil moisture retrieval. The Hydraprobe Data Acquisition System (HDAS) - a dielectric probe - was also used to measure top $5 \mathrm{~cm}$ intensive in situ soil moisture data at $250 \mathrm{~m}$ grid spacing coincident with airborne sampling. The intensive HDAS soil moisture measurements were collected to evaluate the performance of airborne PLMR soil moisture retrievals.

The PLMR radiometric brightness temperature observations were used to derive a reference airborne soil moisture data set. This retrieval process included application of the L-band Microwave Emission of the Biosphere (L-MEB, Wigneron et al., 2007) radiative transfer model 
to PLMR brightness temperature (Ye et al., in review). The vegetation water content used by the L-MEB model for soil moisture retrieval was estimated using the relationships developed by Gao et al. (2015), which convert the derived Normalized Difference Vegetation Index (NDVI, Rouse et al., 1974) from daily 250 m MODerate resolution Imaging Spectroradiometer (MODIS) reflectance products (MOD09GQ) to vegetation water content. Utilized surface roughness and vegetation parameters were obtained from Panciera et al. $(2008,2009)$ and information about land surface types were collected from the studies conducted by Grant et al. (2008) and Wigneron et al. (2007). In order to estimate effective soil temperature, the average of soil temperature measurements at 2.5 and $40 \mathrm{~cm}$ depth were calculated using measurements from the six temporary monitoring stations over the Yanco area.

In order to quantify the accuracy of the reference airborne PLMR soil moisture maps and their propagation into the evaluation statistics for the downscaled soil moisture, the airborne PLMR soil moisture retrievals were compared against the HDAS measurements over all intense soil moisture sampling areas for SMAPEx-4 and -5 airborne field campaigns (Figure 3). The intensive HDAS soil moisture measurements were averaged to $3 \mathrm{~km}$ for the comparison with the airborne PLMR soil moisture aggregated to $3 \mathrm{~km}$. While overall evaluation of $3 \mathrm{~km}$ PLMR soil moisture pixels are reported in Figure 3, the accuracy assessment was also conducted for each dominant land surface type with similar results. An overall RMSD of $0.04 \mathrm{~m}^{3} \mathrm{~m}^{-3}$ and $\mathrm{R}^{2}$ of 0.76 was achieved for $3 \mathrm{~km}$ SMAPEx- 4 and -5 soil moisture data, showing that airborne soil moisture could be used as a suitable reference for evaluation of downscaled soil moisture products. The PLMR soil moisture maps at $1 \mathrm{~km}$ were not evaluated in a similar way as there were only a few HDAS intense soil moisture measurements $(\leqslant 4)$ available within each $1 \mathrm{~km}$ footprint, yielding the analysis unreliable. In addition, the HDAS measurements within the 1 $\mathrm{km}$ scale had a large variability due to the range of moisture condition. 


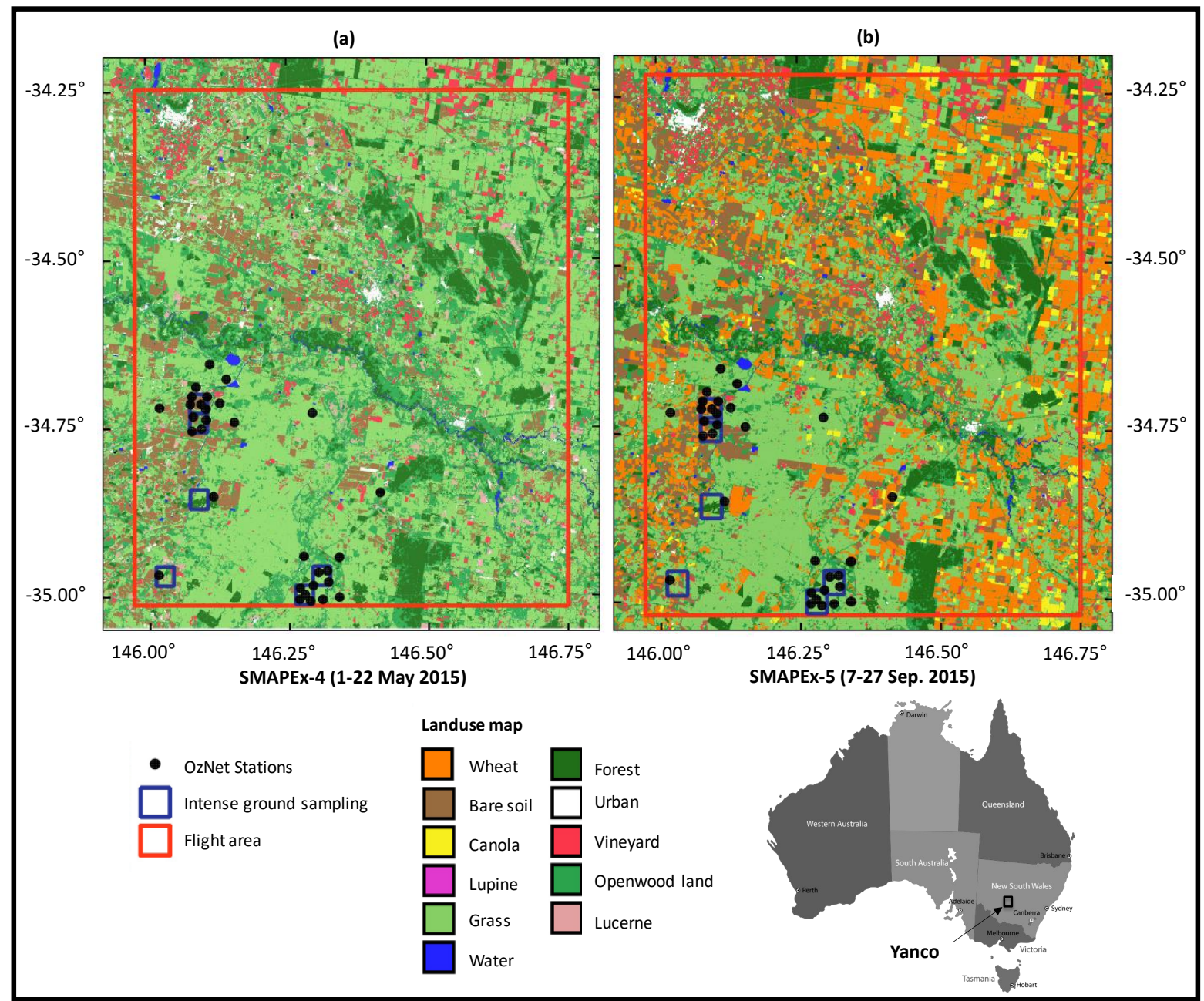

Figure 1: The study area for (a) SMAPEx-4 and (b) SMAPEx-5 airborne field campaigns conducted in the Yanco region in south east of Australia along with red rectangles which delineate the coverage of airborne measurements of each campaign, being $71 \mathrm{~km} \times 85 \mathrm{~km}$ for SMAPEx- 4 and $71 \mathrm{~km} \times 89 \mathrm{~km}$ for SMAPEx-5. Blue rectangles show the locations of the intense ground samplings and black dots are the OzNet in situ monitoring stations. Note: the landuse maps were created using two Landsat-8 Operational Land Imager (OLI) images at $30 \mathrm{~m}$ spatial resolution, acquired on the 10th of June and 30th of September 2015, to match the dates of the SMAPEx-4 and -5 airborne field campaigns.

\section{Downscaling Methods}

This study comprehensively evaluated the performance of soil moisture downscaled products against each other in terms of accuracy and capability to capture the variability of soil moisture in space and time. The products were derived from a variety of current downscaling techniques, categorized as either radar-, optical-, radiometer-and oversampling-based techniques. The soil moisture products evaluated in this study are listed in Table 1 along with the downscaling techniques and approaches, product definitions, key references, and main downscaling inputs as 


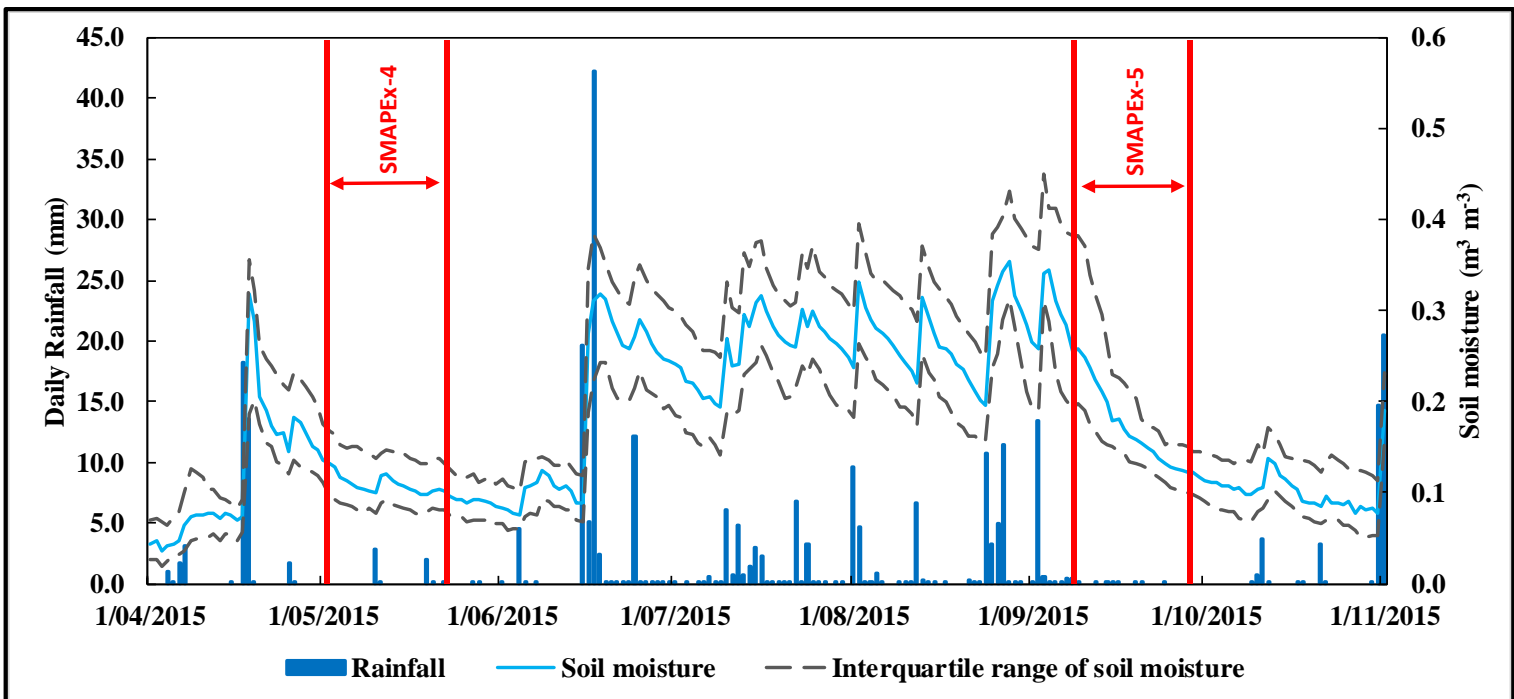

Figure 2: Time series of the OzNet top $5 \mathrm{~cm}$ in situ soil moisture and rainfall measurements for the period between 1st April and 1st November 2015 used in this study. The solid light blue line and dashed gray lines show the median and interquartile range of soil moisture measurements, respectively. The dark blue bars show the mean daily rainfall over the Yanco region.

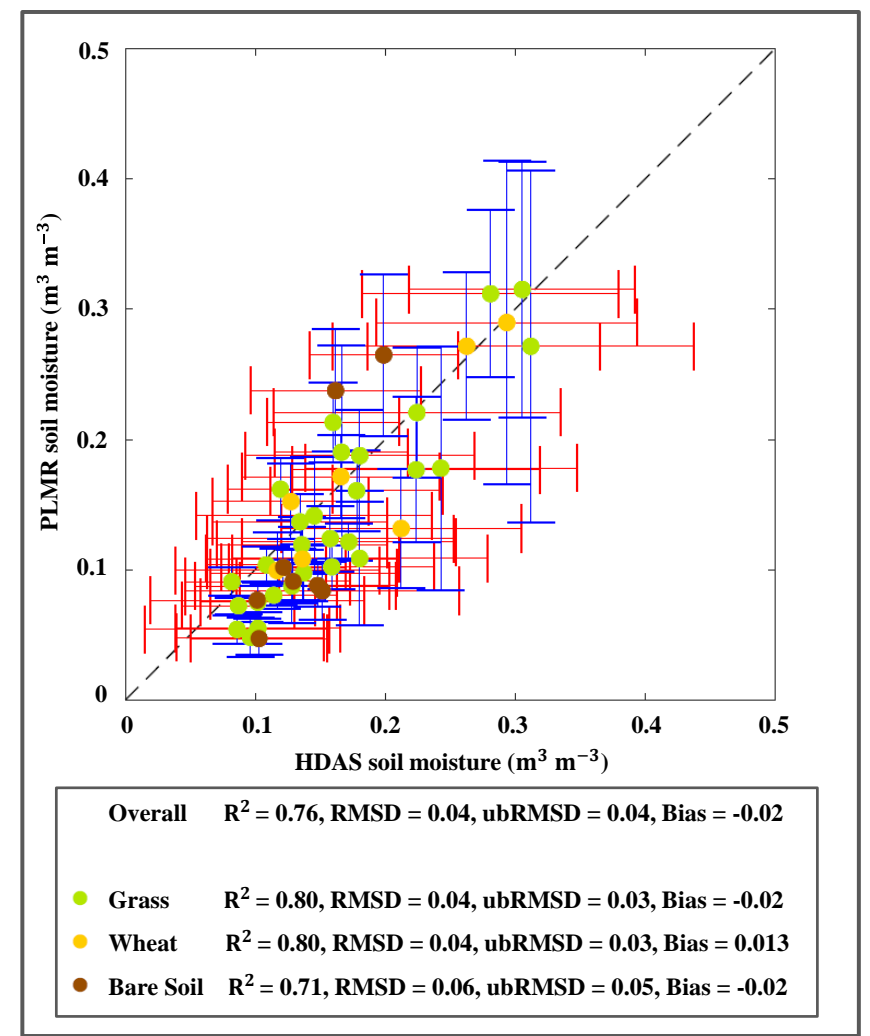

Figure 3: Comparison of SMAPEx-4 and -5 PLMR soil moisture estimates at $3 \mathrm{~km}$ against aggregated intense HDAS soil moisture measurements to $3 \mathrm{~km}$. Whiskers in red show the standard deviation of aggregated HDAS measurements to $3 \mathrm{~km}$, while whiskers in blue show the standard deviation of aggregated PLMR soil moisture estimates to $3 \mathrm{~km}$. 
applicable. The downscaling techniques were benchmarked against the SMOS and SMAP coarse passive microwave observations to provide insight about the impact of downscaling approaches on the accuracy of soil moisture retrievals, and inter-compared over the Yanco region using the airborne soil moisture maps collected during the SMAPEx-4 and -5 airborne field campaigns, as well as OzNet in situ measurements for the period between 1 April and 1 November 2015. The intention of this comparison was to reveal if downscaled soil moisture products surpass the coarse passive soil moisture estimates in terms of accuracy, and to quantitate the extent of possible improvement (or deterioration). In this study, the SMAP Level 3 Radiometer Global Daily soil moisture (version 3) posted on the $36 \mathrm{~km}$ EASE-Grid, and the daily global SMOS Level 3 radiometric soil moisture retrievals, obtained from the $43 \mathrm{~km}$ mean spatial scale SMOS observations posted on the $25 \mathrm{~km}$ grid (SMOS operational MIR CLF31A/D version 3.00 obtained from the CATDS website: https://www.catds.fr/Products/Products-access), were evaluated for this purpose.

\section{Radar-based techniques}

The SMAP soil moisture was downscaled from 36 to $9 \mathrm{~km}$ using the radar-based downscaling techniques, including: i) the baseline active/passive method of SMAP (Das et al., 2014) and, ii) the Multi-Objective Evolutionary Algorithm (MOEA) by Akbar et al. (2016). The baseline active/passive combination technique is the main procedure used by the SMAP science team to produce the SMAP Radar/Radiometer soil moisture products at $9 \mathrm{~km}$ resolution prior to the radar failure. This downscaling algorithm was developed to take advantage of the strengths of passive and active microwave observations, being accurate and high resolution soil moisture mapping, respectively. The baseline algorithm disaggregated the SMAP radiometric brightness temperature through combination with SMAP radar backscatter. This procedure, which inherited background knowledge from the work of Piles et al. (2009) and Das et al. (2011), includes: i) calibrating model parameters from a linear regression analysis of the time series of brightness 


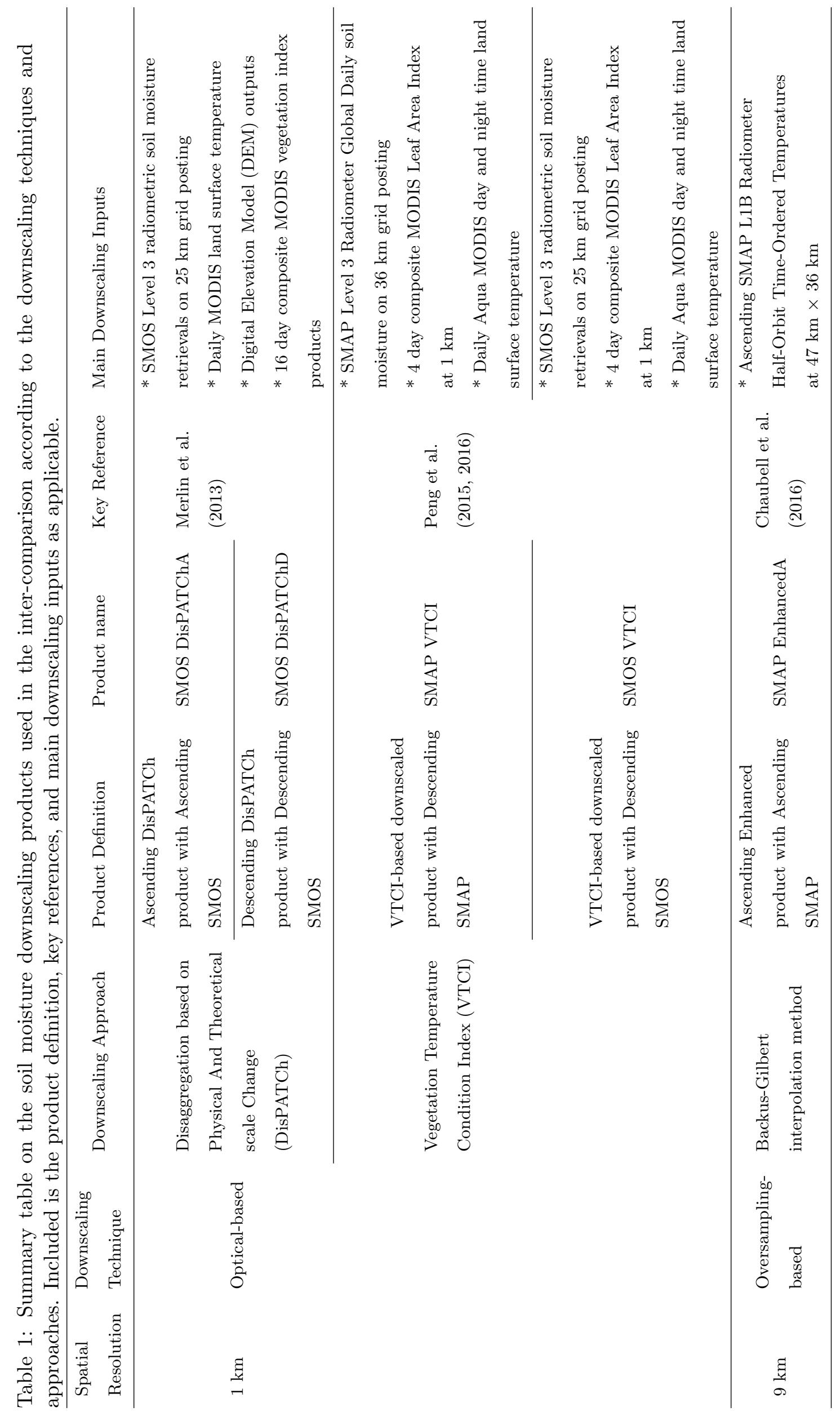




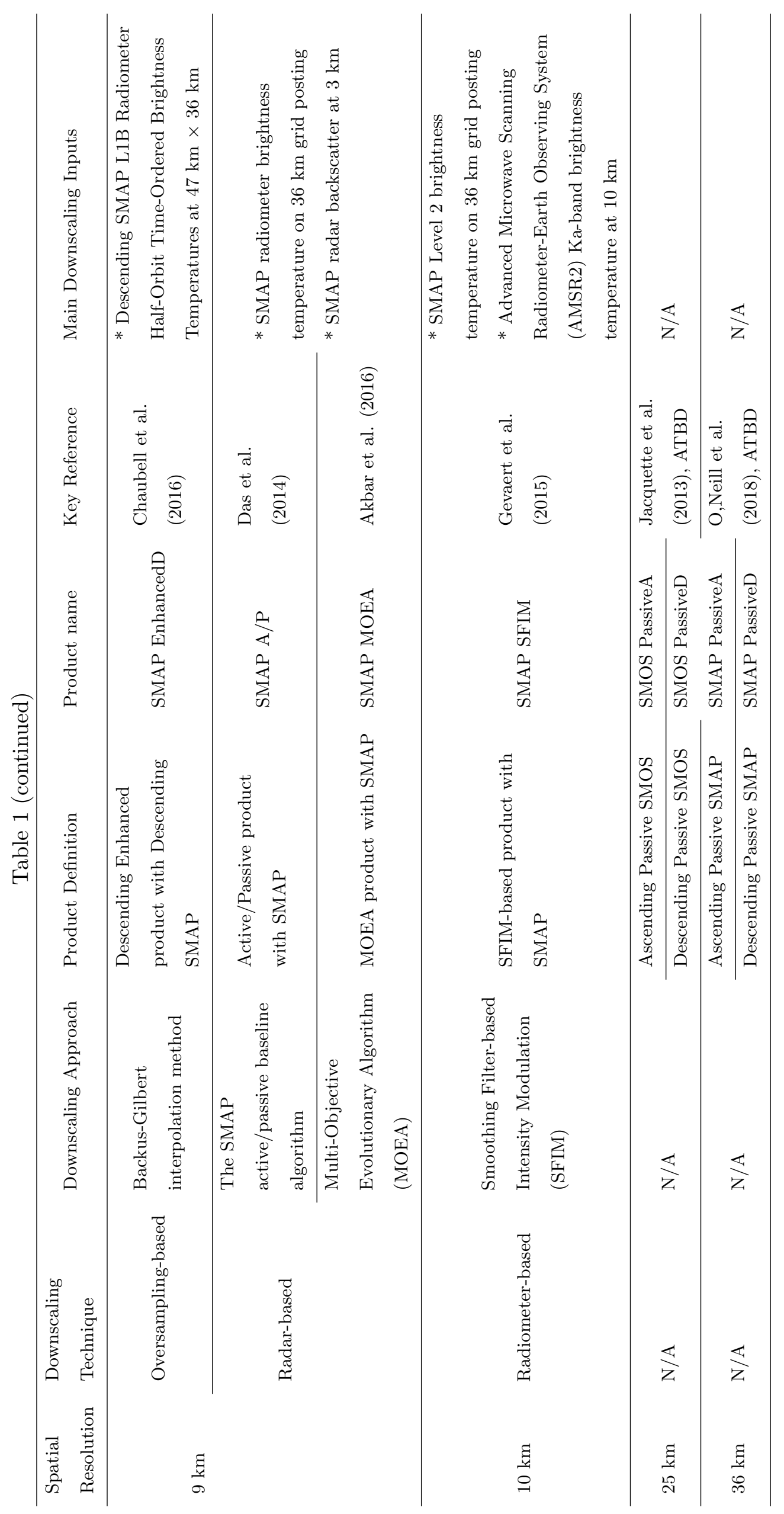


temperature-radar backscatter pairs at radiometric footprint (36 km), and ii) combination of the coarse resolution brightness temperature and medium resolution radar backscatter (9 km) using a linear function, which utilizes the calibrated slope from the predecessor step. Soil moisture is then estimated by applying the radiative transfer model (single channel algorithm, Jackson, 1993) to the downscaled brightness temperature. These estimates are available at the NASA National Snow and Ice Data Center Distributed Active Archive Center (NSIDC DAAC) website as SMAP Level 3 Radar/Radiometer Global Daily 9 km EASE-Grid Soil Moisture, Version 3 (SPL3SMAP, access link: https://nsidc.org/data/SPL3SMAP/versions/3).

The MOEA is a physical-based downscaling technique (Akbar et al., 2016), which implicitly disaggregates the radiometric soil moisture from the coarse scale of $36 \mathrm{~km}$ to the medium scale of $9 \mathrm{~km}$ using a multi-objective optimization approach. This technique is based on the combination of optimized radar- and radiometer-only soil moisture estimations and is developed to compromise on the performance of the forward electromagnetic emission and scattering models. The MOEA technique finds an optimum solution by including evaluation of multiple objective functions within each iteration. Based on stochastic operators, the MOEA procedure gives more weight to the most accurate soil moisture retrievals from either radar backscatter or brightness temperature. The MOEA technique was applied to the SMAP L2 Radiometer Half-Orbit 36 km EASE-Grid Soil Moisture, Version 2 and SMAP L1C Radar Half-Orbit High-Resolution $\sigma^{\circ}$ Data on $1 \mathrm{~km}$ Swath Grid, Version 1 (SPL1CS0) pairs.

\section{Optical-based Techniques}

Two types of physically based optical downscaling techniques were applied to the daily global SMOS Level 3 radiometric soil moisture retrievals, obtained from the $43 \mathrm{~km}$ mean spatial scale SMOS observations posted on the $25 \mathrm{~km}$ grid (SMOS operational MIR CLF31A/D, version 3.00 obtained from the Centre Aval de Traitement des Données SMOS (CATDS) website) and SMAP Level 3 Radiometer Global Daily soil moisture posted on the $36 \mathrm{~km}$ EASE-Grid. Disaggregation 
was based on the Physical And Theoretical scale Change (DisPATCh; Merlin et al., 2013) and the Vegetation Temperature Condition Index (VTCI; Peng et al., 2015, 2016) approaches to achieve a $1 \mathrm{~km}$ spatial resolution.

The DisPATCh uses the Soil Evaporative Efficiency (SEE, i.e. ratio of actual to potential soil evaporation) derived from the daily MODIS land surface temperature (MOD11A1 and MYD11A1 products) and a 16 day composite MODIS vegetation index product (MOD13A2) at $1 \mathrm{~km}$ resolution, as the main soil moisture downscaling component. MODIS land surface temperature is decoupled in its soil and vegetation components based on a partitioning method (Moran et al., 1994) with the decoupled surface temperature corrected for the impact of elevation using an ancillary $1 \mathrm{~km}$ resolution Digital Elevation Model (DEM) according to Merlin et al. (2013). The SEE proxy is an appropriate downscaling index because: i) it has a relatively constant daily characterization for non-cloudy skies (Cragoa and Brutsaert, 1996) and ii) it corresponds well with soil moisture changes (Anderson et al., 2007). The DisPATCh technique was applied to the SMOS ascending and descending soil moisture observations resulting in two DisPATCh products, the morning/ascending DisPATCh (DisPATChA) and afternoon/descending DisPATCh (DisPATChD).

The VTCI technique uses the high resolution VTCI as the downscaling factor. The VTCI is a thermal based proxy which is used as a drought monitoring index (Wang et al., 2001). It is calculated based on the triangular/trapezoidal feature space constructed from 4 day composite MODIS Leaf Area Index (LAI, MCD15A3) at $1 \mathrm{~km}$ resolution and the daily Aqua MODIS dayand night-time land surface temperature difference $\left(\Delta \mathrm{LST}_{\text {day }- \text { night }}, \mathrm{MYD} 11 \mathrm{~A} 1\right)$.

\section{Radiometer-based techniques}

Downscaled SMAP soil moisture retrievals were also produced at $10 \mathrm{~km}$ using the radiometerbased Smoothing Filter-based Intensity Modulation (SFIM) model used by Gevaert et al. (2015).

The SFIM methodology is based on the multi-sensor image fusion technique designed by (Liu, 
2000). Success of this technique in producing downscaled Landsat Thematic Mapper data to a higher spatial resolution using the high resolution Satellite Pour l'Observation de la Terre images, motivated Santi (2010) to employ this technique for the purpose of soil moisture downscaling. In the SFIM procedure a weighting factor is used to downscale the $36 \mathrm{~km}$ SMAP Level 2 brightness temperature (SPL2SMP) to $10 \mathrm{~km}$. The downscaling factor used here is the ratio between the Advanced Microwave Scanning Radiometer-Earth Observing System (AMSR2) Ka-band brightness temperature for each grid cell at $10 \mathrm{~km}$ and the average of Ka-band brightness temperature across the coarse scale of the SMAP brightness temperature observations. From downscaled SMAP brightness temperature, soil moisture content was estimated through application of the Land Parameter Retrieval Model (LPRM, Owe et al., 2001, 2008).

\section{Oversampling-based techniques}

An oversampling-based technique (Chan et al., 2018; Chaubell, 2016), based on the BackusGilbert interpolation method (Backus and Gilbert, 1970, 1967), was also used to enhance not only the spatial scale of SMAP brightness temperature but also its accuracy. Soil moisture was then derived by applying a radiative transfer model to the brightness temperature posted onto a $9 \mathrm{~km}$ grid. This technique was applied to the morning/descending (D) and afternoon/ascending (A) SMAP level 1B Radiometer Half-Orbit Time-Ordered brightness Temperature products at $47 \mathrm{~km} \times 36 \mathrm{~km}$, resulting in two series of products: the EnhancedD and EnhancedA, respectively. Free access to the SMAP enhanced soil moisture products is granted (https://nsidc.org/data/SPL3SMP_E/versions/2). The Backus-Gilbert is an optimal interpolation theory that provides the closest observation to what perhaps would be measured by the radiometric instrument at the interpolation point (Poe, 1990). To this aim, all the brightness temperature values that are centred near a particular radius within a relatively short length of intervals are aggregated to a spatial resolution higher than the resolution and/or footprint of observations. The extent of improvement of the spatial resolution is determined by the sampling 
density and the overlap in the response functions of the instrument at measurement locations. Long and Daum (1998) found out that when the sampling pattern is denser there is a better opportunity for the spatial resolution enhancement of observations. The non-uniformity of overlapping measurement is another factor which facilitates better resolution enhancement (Long, 2003).

\section{Evaluation methodology}

This section describes the evaluation procedure that is summarised in Figure 4. Here downscaled products are evaluated against a comprehensive reference data set that includes the OzNet in situ soil moisture measurements and SMAPEx-4 and -5 airborne PLMR soil moisture maps. The coarse passive SMAP and SMOS soil moisture products were also compared against the same reference data set providing a baseline scenario. Unlike previous studies (e.g. Al-Yaari et al., 2019; Chen et al., 2018) which assessed the accuracy of SMAP and SMOS passive microwave soil moisture products at their coarse scale (posted onto 36 and $25 \mathrm{~km}$ spatial resolution, respectively), this study only assessed the accuracy of the coarse resolution products in the context of being a reference for assessing the skill of the downscaled products relative to the uniform field assumption. Accordingly, this assessment was to understand to what extent the downscaling techniques improved the spatial soil moisture estimates over the simplistic assumption that the soil moisture is a uniform field over coarse resolution pixels. This evaluation is meant to serve as a quantitative assessment of the improvement in the downscaled products over the coarse soil moisture products, applied directly at the same spatial resolution as the comparable downscaled product. Consequently, prior to the evaluation of coarse SMAP and SMOS soil moisture products, each product was mapped onto a 1 and $9 \mathrm{~km}$ grid, with the value of each coarse pixel assigned to each higher resolution pixel lying within the original pixel.

The evaluation against OzNet measurements was conducted over the period between 1st April and 1st November 2015, while the time frame of the evaluation against airborne PLMR 


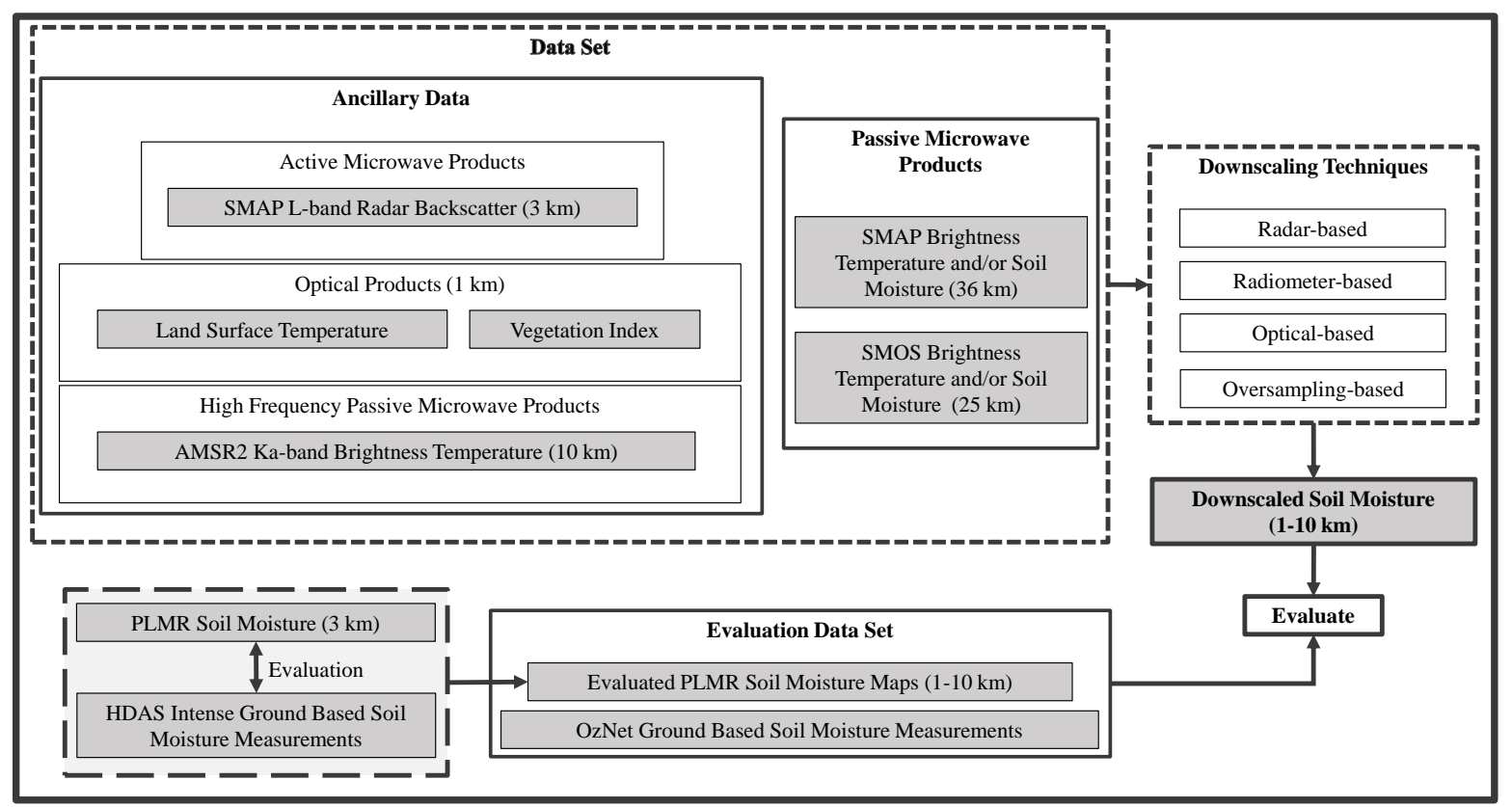

Figure 4: Schematic of the procedure used for evaluation of the downscaled soil moisture retrievals against airborne PLMR and OzNet in situ soil moisture measurements.

soil moisture was associated with the temporal extent of the SMAPEx-4 and -5 airborne field campaigns. The evaluation included a temporal analysis of downscaled products against both the OzNet and airborne PLMR soil moisture. In the temporal analysis, time series of soil moisture values from each pixel of modelled estimates were compared against corresponding values from the reference PLMR maps and/or aggregated OzNet measurements to the products pixel scale. Moreover, the spatial analysis was carried out against the airborne PLMR soil moisture. In the spatial analysis, daily maps of estimates were compared against the corresponding reference map. From the temporal and spatial match-ups mentioned above, the performance metrics were calculated, including bias, coefficient of determination $\left(\mathrm{R}^{2}\right)$, Root Mean Square Deviation (RMSD), unbiased RMSD (ubRMSD), and slope of the linear regression. In order to provide readers with more information about the performance of soil moisture products, relative accuracy of the soil moisture products was calculated and reported in the Appendix. The relative accuracy parameters were calculated by dividing Bias, RMSD, and ubRMSD values by the average of reference soil moisture content values through time and space for temporal and spatial analysis, respectively. 
The optical-based downscaled products were evaluated at two different scales: i) $1 \mathrm{~km}$ being the original scale of the optical-based products, and ii) $9 \mathrm{~km}$ being the scale of radar- and oversampling-based retrievals. For the evaluation at $9 \mathrm{~km}$, the optical-based products herein DisPATCh and VTCI were upscaled to the SMAP A/P scale of $9 \mathrm{~km}$, using the arithmetic average. The evaluation at $9 \mathrm{~km}$ was conducted to make the comparison system consistent across downscaled soil moisture products being mainly available at $9 \mathrm{~km}$.

\subsection{Evaluation against $\mathrm{OzNet}$ in situ soil moisture measurements}

To compare downscaled products against OzNet, soil moisture measurements from individual stations were averaged within the grid cell of each product. However, for the $1 \mathrm{~km}$ grid, any pixel with a coincident OzNet station was considered for comparison. Therefore, 28 and 30 pixels at the $1 \mathrm{~km}$ scale of the DisPATCh and VTCI products, respectively, were compared against the corresponding OzNet stations. For the grid scales larger than $1 \mathrm{~km}$, comparisons were made across the pixels that had a large number of OzNet stations (more than or equal to four) within their scale. Figure 5 shows the selected pixels at the medium scales of 9 and 10 $\mathrm{km}$ at which downscaled soil moisture products were evaluated.

\subsection{Evaluation against SMAPEx-4 and -5 PLMR soil moisture maps}

The evaluation of downscaled products against PLMR required pairing of the PLMR soil moisture maps with the nearest available downscaled products to the PLMR flights, when coincident downscaled data were not available. The nearest available products were selected based on information about the rainfall occurrence over the study area and minimal average absolute change $\left(\leq 0.02 \mathrm{~m}^{3} \mathrm{~m}^{-3}\right)$ of OzNet soil moisture measurements between the flight dates and those of the nearest available products in time. The date of the nearest available observations to PLMR flights is written on soil moisture thumbnail plots (Figure 6 and 7 provided in the results section) when data were not coincident. To resolve scale mismatches between soil moisture products 


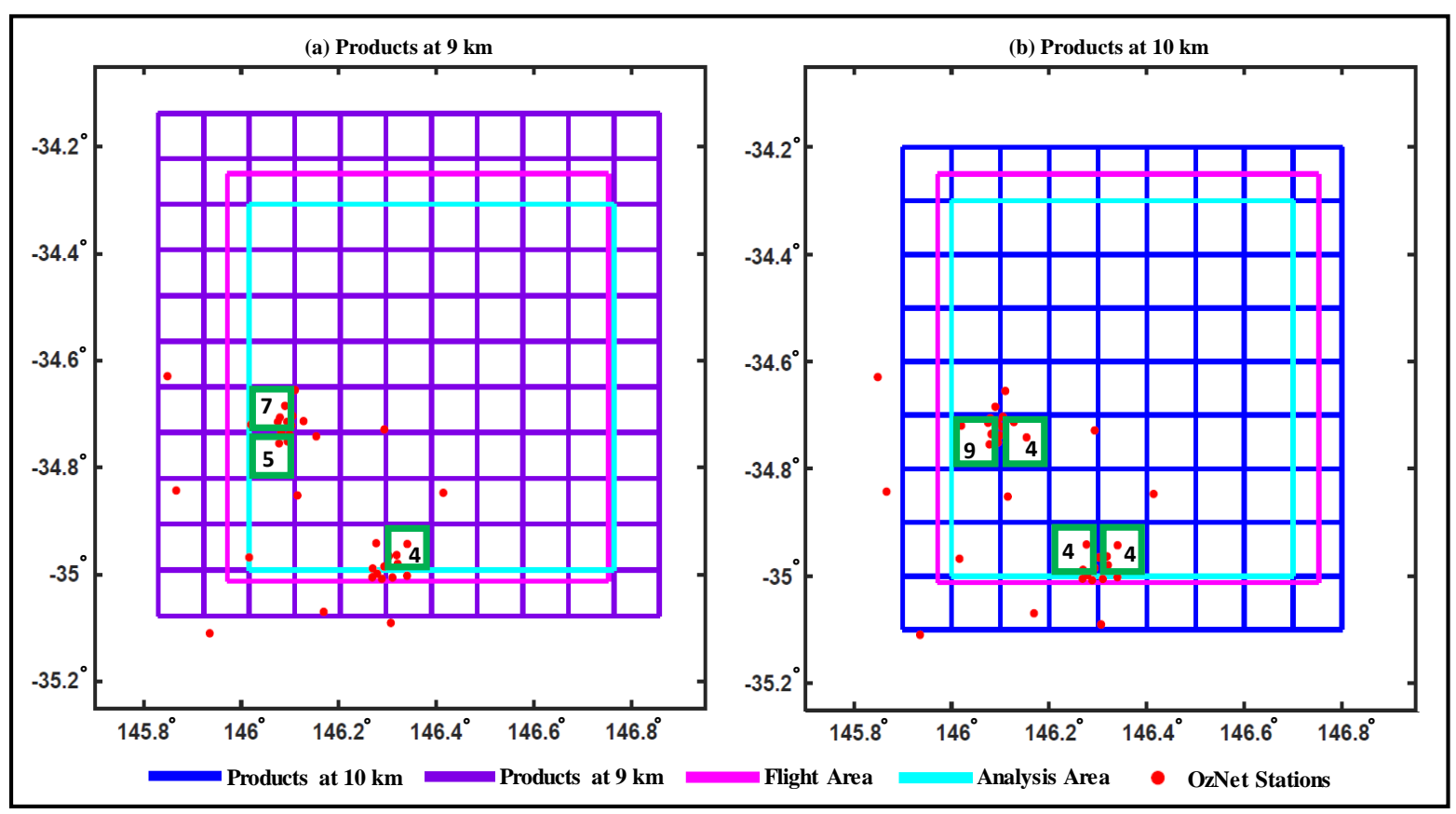

Figure 5: Schematic of the downscaled soil moisture product grids at (a) $9 \mathrm{~km}$ and (b) 10 $\mathrm{km}$. The SMAPEx-4 and -5 flight coverage and location of OzNet stations are highlighted in magenta rectangles and red dots, respectively. The cyan rectangle shows the common analysis area for both airborne field campaigns. Green squares show the chosen pixels for analysis of soil moisture products against OzNet measurements. These pixels contain the largest number of OzNet stations (more than four); the number of available stations is written in the pixel.

and PLMR soil moisture maps, the original PLMR soil moisture footprints were first processed onto the same $1 \mathrm{~km}$ grid, and then averaged within the grid cell of each 9 or $10 \mathrm{~km}$ resolution product.

The main comparison scenario of downscaled products against airborne PLMR soil moisture was developed to discard the seasonal performance of downscaled products because the operational application of downscaled soil moisture products should be regardless of climate conditions (Sabaghy et al., 2018). The analysis herein used the entire downscaled soil moisture data captured during both the SMAPEx-4 and -5 airborne field campaigns. Moreover, the seasonal performance of downscaled soil moisture products was examined for the Austral autumn (March-May, using SMAPEx-4 data) and spring (September-November using SMAPEx-5 data) as a complementary scenario, in order to understand the seasonal performance and uncertainties of the soil moisture products.

Radar-based soil moisture products were only available for the period between 15 April and 
7 July 2015 when the SMAP radar was still transmitting data. Thus, radar-based products were evaluated only for the SMAPEx-4 airborne field campaign. The seasonal evaluation of the performance of other downscaled products was conducted when enough (4 or more) coincident downscaled soil moisture maps were available. Accordingly, the performance analysis of the VTCI-based products was not possible for the SMAPEx-4 period as only one SMOS VTCI and two SMAP VTCI soil moisture maps were captured due to cloud.

In order to address the potential variation in number of different downscaled products available for comparison, and eliminate the impact on evaluation, only downscaled products collected on 3, 6, 11, 20 and 22 May 2015 during SMAPEx-4 were evaluated herein. This evaluation was undertaken for the SMAPEx-4 period only because the radar-, optical-, radiometer-and oversampling-based products were all available over this period.

\section{Results}

Time series of downscaled and observed airborne PLMR soil moisture maps during the SMAPEx4 and -5 airborne field campaigns are shown in Figure 6 and Figure 7, respectively. These figures show the performance of the downscaled products in capturing the spatio-temporal variability of soil moisture. The airborne PLMR soil moisture estimates at $1 \mathrm{~km}$ have consistency with the occurrence of precipitation events, mimicking the dry down cycle observed during SMAPEx-5 and the rainfall interrupted drying spell during the SMAPEx-4 (Figure 2). There is no clear evidence from Figures 6 and 7 to show that any downscaling process is clearly superior to another for disaggregation of SMAP and/or SMOS, but among the downscaled products available over the SMAPEx-4 period, DisPATCh and VTCI products - especially at $9 \mathrm{~km}$ - revealed the best visual agreement with the spatial and temporal pattern of airborne PLMR soil moisture compared to other products. However, a limitation of the optical approach is that it cannot deliver any soil moisture downscaling under cloudy skies because of the lack of cloud-free optical imagery, which is the key component or input in the optical downscaling process. This short- 


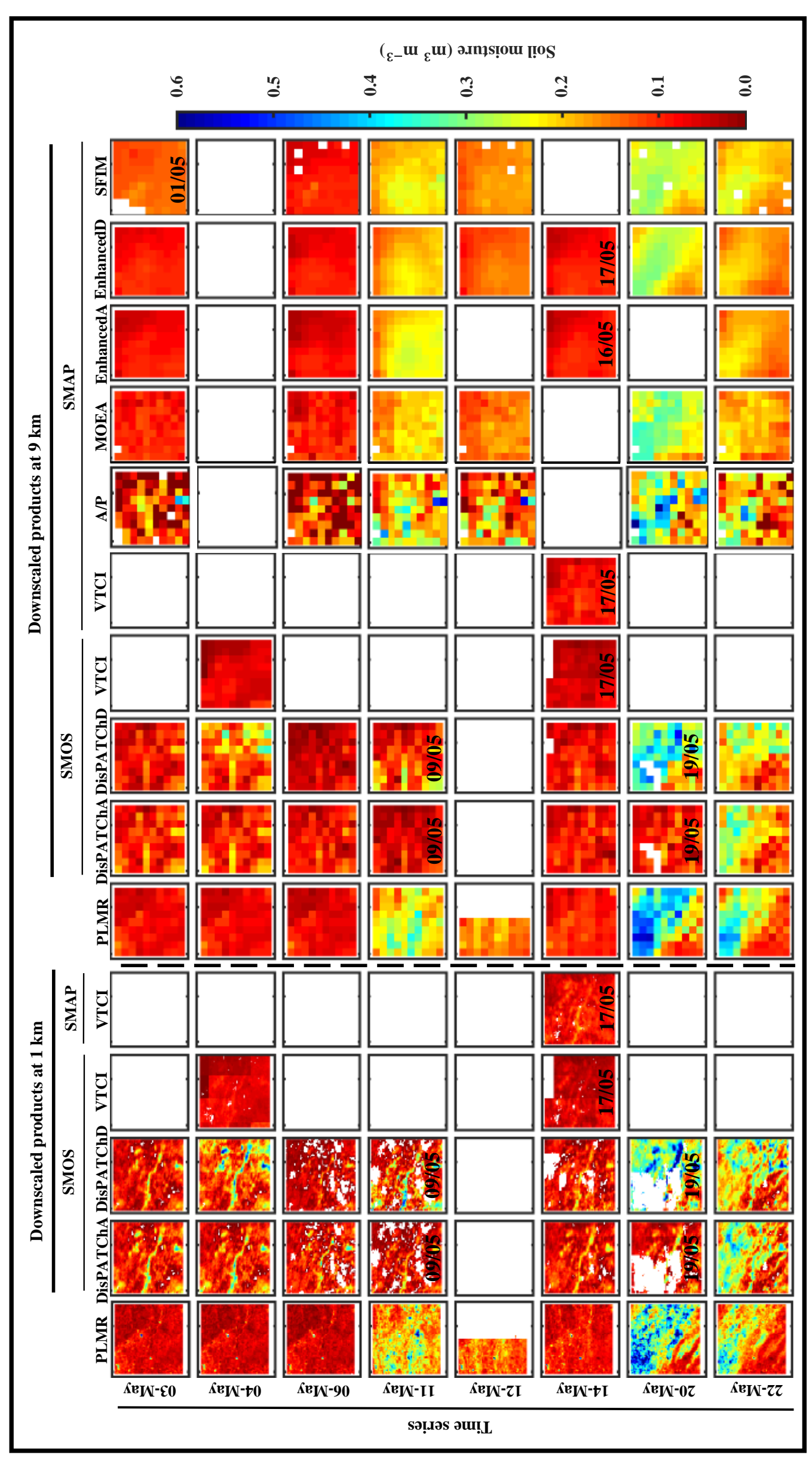

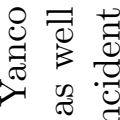

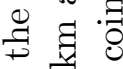

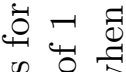

过

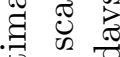

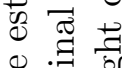

.0.0

可 0

옹

द्व

웅

다

『

की

है

0 .

in 0

Do

$\Phi$.

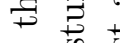

결

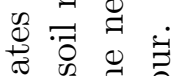

द्व

मे

क

드용

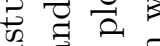

궁

$=$ 菏

क 0 을

记

5 o

氙

$\rightarrow$ च

是焉

征产

角

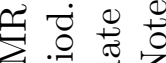

至

a 20.

岁计

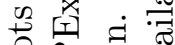

을 월

क

费 0

o \& 0

0 झ

的我离要

$\ddot{\theta} \Xi$

0 手 ప. 00 I 


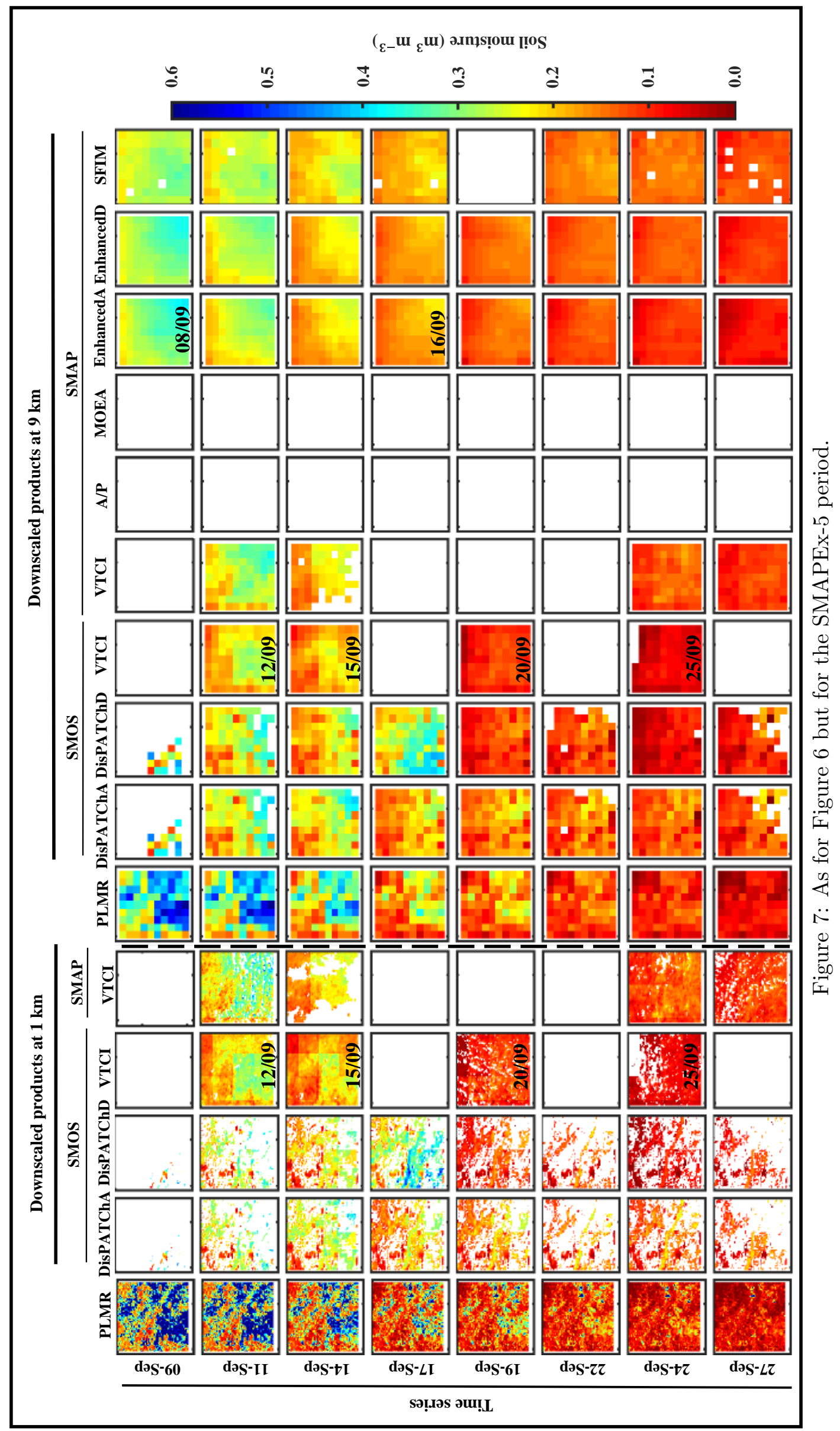


coming of optical imagery resulted in the reduced availability of the VTCI-based downscaled soil moisture, which uses the difference of day and night land surface temperature in derivation of its downscaling index. The lack of access to optical observations, which is more pronounced for the SMAPEx-5 period, is unlike microwave-based approaches where there are no such gaps in data. The microwave-techniques are in general capable of soil moisture downscaling under all-weather conditions. This capability is due to microwave observations being able to pass through non-raining clouds unaffected. The success of DisPATCh and VTCI products in capturing the soil moisture spatio-temporal variability is followed by the radar-based downscaled product, namely the SMAP MOEA, which was only available for the SMAPEx-4 period.

The temporal evolution of downscaled soil moisture products at $9 \mathrm{~km}$ was also compared with that of aggregated OzNet measurements to $9 \mathrm{~km}$ (Figure 8) showing a significant level of agreement between them. The majority of downscaled soil moisture values do not match the median OzNet soil moisture closely, but are in the range of aggregated OzNet measurements. However, there are also a few days on which downscaled soil moisture estimates laid outside the OzNet measurement range. Erratic oscillations were observed for the SMOS PassiveD soil moisture estimates between July to September 2015. These oscillations are reportedly due to a poor constraint on the Vegetation Optical Depth (VOD) during the retrieval process. This is specific to the level 3 algorithm used in this analysis (SMOS operational MIR CLF31A/D product, version 3.00) and does not occur with the level 2 algorithm. Accordingly, a new level 3 retrieval algorithm has recently been developed by the SMOS science team to constrain VOD during 3-orbit periods and is currently being validated. The accuracy of downscaled soil moisture products is known to be affected by the accuracy of the coarse passive soil moisture from which downscaled products are derived (Peng et al., 2017; Sabaghy et al., 2018). Accordingly, the soil moisture values larger than $0.55 \mathrm{~m}^{3} \mathrm{~m}^{-3}$ were excluded from the statistical analysis. However, the SMOS DisPATChD and SMOS VTCI downscaled soil moisture estimates were shown to rarely reach values larger than $0.5 \mathrm{~m}^{3} \mathrm{~m}^{-3}$ in mid August, similar to SMOS PassiveD 


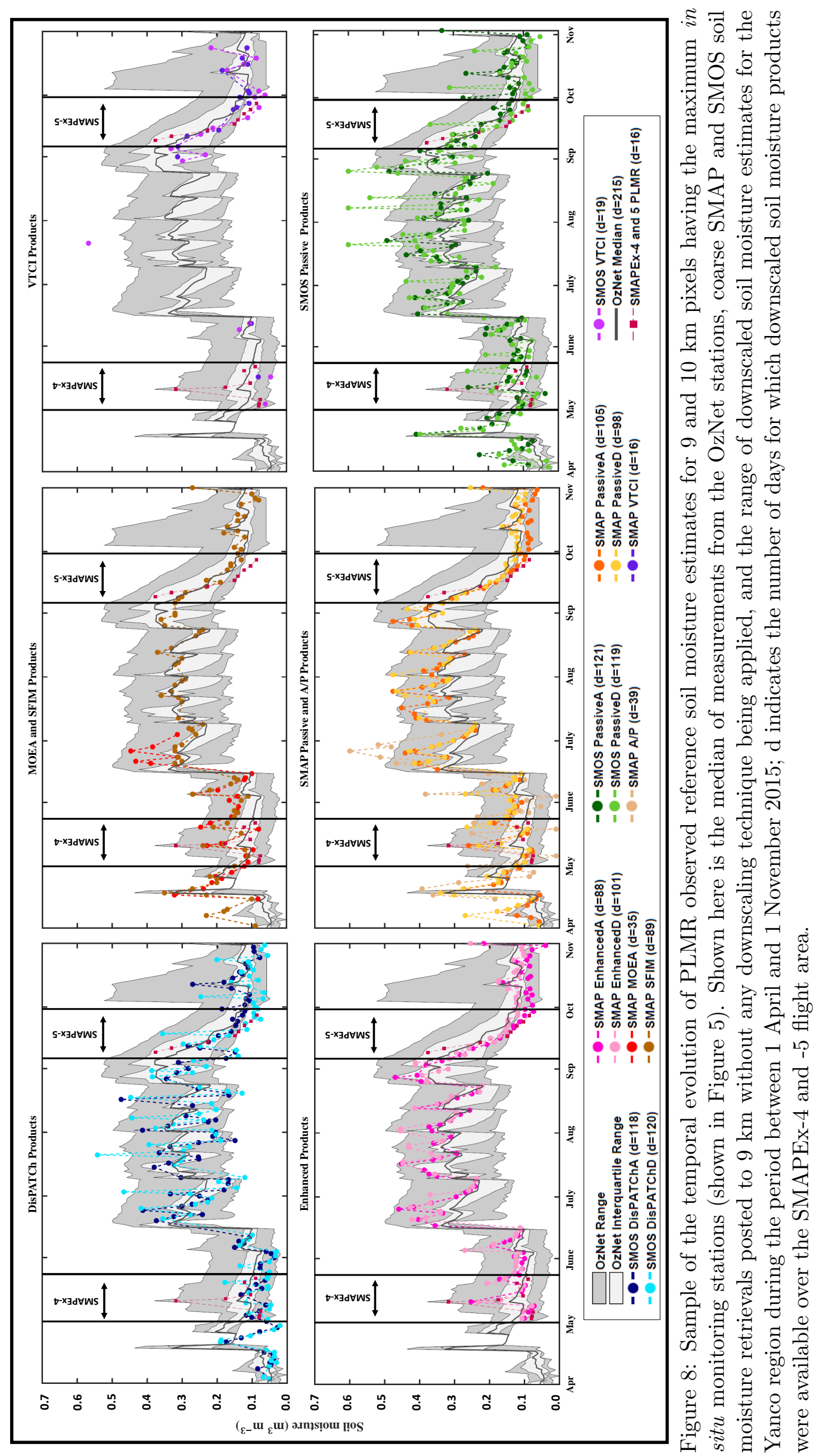


soil moisture estimates. While the SMAP Passive soil moisture estimates shown in Figure 8 were shown to be less than $0.47 \mathrm{~m}^{3} \mathrm{~m}^{-3}$, the SMAP A/P soil moisture estimate on late June 2015 was shown to be more than $0.5 \mathrm{~m}^{3} \mathrm{~m}^{-3}$. This is explained as follows: if the $36 \mathrm{~km}$ SMAP Passive soil moisture is $0.47 \mathrm{~m}^{3} \mathrm{~m}^{-3}$, as in this case, it is expected that some downscaled pixels at higher spatial resolution will get wetter while some will get drier to compensate and maintain the same average value as the coarser pixel.

This analysis assessed the accuracy of downscaled soil moisture products regardless of subpixel surface heterogeneity and land cover types across the Yanco region, as downscaling techniques should be applicable for a wide range of surface and vegetation cover conditions if they are to be applied operationally. However, the dominant vegetation cover at 1 and $9 \mathrm{~km}$ spatial resolution for the SMAPEx-4 and -5 airborne field campaigns are available in Figure A1 of the Appendix to provide detailed information about vegetation cover over the study area.

\subsection{Temporal analysis against $\mathrm{OzNet}$}

Temporal analysis of soil moisture products was carried out against pixels containing multiple OzNet stations. In this analysis, time series of soil moisture values from the chosen pixels were compared against corresponding values from aggregated OzNet soil moisture measurements. A summary of accuracy statistics from different downscaled products is presented as a boxplot in Figure 9, containing the minimum, maximum, median, and interquartile ranges together with the mean.

\section{Evaluation of products at $1 \mathrm{~km}$}

When compared against aggregated OzNet measurements at $1 \mathrm{~km}$ (Figure 9-a), the products were shown to have a poorer performance than the products at $9 \mathrm{~km}$. Such a decrease in the performance of products at $1 \mathrm{~km}$ could be associated with the spatial-scale mismatch, which is expected to be larger for higher resolution products (van der Velde et al., 2012). Moreover, 
it has previously been noted by Yee et al. (2016) that the evaluation of soil moisture products against OzNet stations in the Yanco region is indicated a better accuracy for coarser resolutions whereby multi-stations are aggregated for each pixel footprint.

The SMAP VTCI with mean $\mathrm{R}^{2}$ of 0.85 and mean RMSD of $0.07 \mathrm{~m}^{3} \mathrm{~m}^{-3}$ was found to have the best performance. The $\mathrm{R}^{2}$ of DisPATCh products at $1 \mathrm{~km}$ were observed to be slightly lower than that of DisPATch products at $9 \mathrm{~km}$. The same observation was made regarding the $\mathrm{R}^{2}$ of SMAP VTCI at $1 \mathrm{~km}$, which did not change much in comparison with that of SMAP VTCI at $9 \mathrm{~km}$; the $\mathrm{R}^{2}$ for $1 \mathrm{~km}$ scaled SMAP VTCI was on average 0.05 less than that of $9 \mathrm{~km}$ SMAP VTCI. Conversely, the $\mathrm{R}^{2}$ of SMOS VTCI at $1 \mathrm{~km}$ was observed to be roughly the same as that of SMOS VTCI at $9 \mathrm{~km}$; similar results were obtained for the SMOS PassiveD from which SMOS VTCI originated. This similarity between the performance of SMOS PassiveD and SMOS VTCI is consistent with previous results reported in Peng et al. (2015, 2016), which showed that VTCI-based downscaled products maintained the accuracy of the original coarse soil moisture products from which they were derived.

Except for SMOS VTCI at $1 \mathrm{~km}$, which slightly underestimated OzNet soil moisture by $-0.004 \mathrm{~m}^{3} \mathrm{~m}^{-3}$ on average, the remaining products overestimated by between 0.012 and 0.046 $\mathrm{m}^{3} \mathrm{~m}^{-3}$ on average. Underestimation of VTCI-based downscaled soil moisture products was also reported by Peng et al. (2015, 2016). With the exception of SMAP VTCI, no improvement of statistical parameters was observed for the $1 \mathrm{~km}$ downscaled products over the original coarse passive SMAP and SMOS soil moisture measurements. However, the accuracy of DisPATChD and SMOS VTCI were shown to be close to that of SMOS PassiveD.

Spatial resolution improvement of downscaled soil moisture products to even higher spatial scale (such as field scale) is not expected to increase the accuracy. For example, Wu et al. (2016) applied the active/passive optional (Das et al., 2011), baseline (Das et al., 2014) and change detection (Piles et al., 2009) retrieval algorithms to the SMAPEx-3 airborne simulation (Wu et al., 2015) of the SMAP data stream to test the robustness of alternate radar-radiometer 
combination algorithms over a semi-arid region. From these alternate downscaling techniques, downscaled soil moisture products were retrieved at three different spatial scales including 1 , 3 , and $9 \mathrm{~km}$. Findings of this study revealed that all of the downscaled products at $9 \mathrm{~km}$ had better performance than the products at 1 and $3 \mathrm{~km}$ spatial resolution in terms of RMSD and spatial resolution improvement, with the downscaled products from 9 to $1 \mathrm{~km}$ deteriorating the statistical metrics.

As suggested by Merlin et al. (2015), the slope of linear regression between downscaled products and OzNet in situ measurements was also considered as an evaluation metric for assessment of products at 1 and $9 \mathrm{~km}$. However, the mean slope values of products at $1 \mathrm{~km}$ varied between 1 and 1.3, showing little difference in the performance of products.

\section{Evaluation of products at $9 \mathrm{~km}$}

Comparison of products at $9 \mathrm{~km}$ resolution (Figure 9-b) shows that the SMAP VTCI soil moisture product had the best temporal agreement with OzNet measurements, followed by the SMAP EnhancedD and EnhancedA products. The SMOS VTCI, SMOS PassiveD and DisPATChD had the lowest agreement with the temporal pattern of OzNet soil moisture compared to other products at $9 \mathrm{~km}$, having an average $\mathrm{R}^{2}$ of $\sim 0.6$. The difference between the performance of the SMAP and SMOS VTCI is the result of the difference in the SMAP and SMOS PassiveD from which the SMAP and SMOS VTCI products were derived. The SMAP VTCI soil moisture had an overall bias of $-0.011 \mathrm{~m}^{3} \mathrm{~m}^{-3}$, which explains the slight underestimation relative to the ground OzNet measurements. While the SMOS VTCI, DisPATChD and SMAP VTCI underestimated relative to OzNet measurements, the other products overestimated. For example, the SMAP MOEA with average bias of $0.057 \mathrm{~m}^{3} \mathrm{~m}^{-3}$ had the most noticeable overestimation.

With the exception of SMAP VTCI and the Enhanced products, other downscaled products at $9 \mathrm{~km}$ showed a deterioration in the $\mathrm{R}^{2}$ when compared with the coarse original SMAP soil 


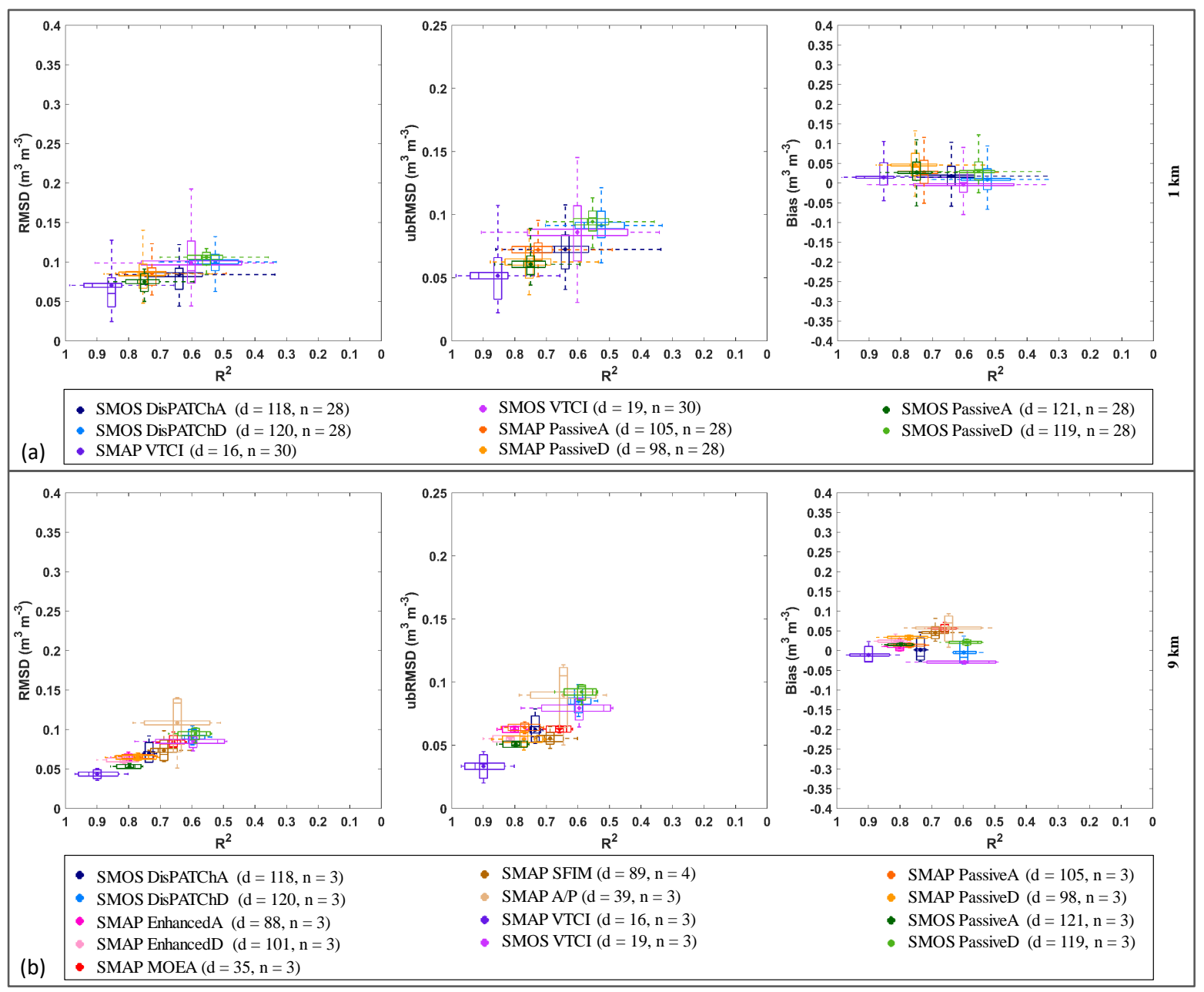

Figure 9: Summary of results obtained from temporal analysis of soil moisture products at (a) $1 \mathrm{~km}$ and (b) $9 \mathrm{~km}$ against OzNet. For $9 \mathrm{~km}$ products, only pixels with the largest number of stations were chosen. Each boxplot displays the distribution of the accuracy statistics of different downscaled products based on the interquartile range, the maximum and minimum range, and the statistics median (bar) associated with the mean (dot). $d$ indicates the number of downscaled products that were used in this analysis and $n$ indicates the number of statistical parameters that are summarized in this figure.

moisture products. For instance, the $\mathrm{R}^{2}$ of SMAP A/P was on average 0.12 less than that of SMAP PassiveA and PassiveD. Inferiority of SMAP A/P to SMAP Passive products in terms of temporal correlation with in situ measurements has also been reported by Mishra et al. (2018), who evaluated SMAP A/P Level 3 soil moisture products using in situ soil moisture measurements from the Soil Climate Analysis Network (SCAN) stations across the Continental United States. The temporal correlation between the SMAP SFIM and in situ OzNet soil moisture measurements also tended to be lower than that of the SMAP Passive soil moisture products, similar to results reported by Gevaert et al. (2015). 
Among the downscaled products, the SMAP EnahncedA and EnhancedD downscaled products maintained a similar RMSD to the coarse SMAP passive soil moisture products. It is to be noted that SMAP VTCI was the only downscaled product which outperformed the original coarse passive SMAP in terms of RMSD, hitting the lowest values of RMSD and ubRMSD. The DisPATChD could not improve the accuracy of non-downscaled SMOS PassiveD from which DisPATChD originated. However, the DisPATChD showed a close performance to that of SMOS PassiveD.

The SMAP EnhancedD with mean $\mathrm{R}^{2}$ of 0.81 , mean RMSD of $0.061 \mathrm{~m}^{3} \mathrm{~m}^{-3}$ and mean bias of $0.024 \mathrm{~m}^{3} \mathrm{~m}^{-3}$ was found to have a slightly better performance than the SMAP EnhancedA. The performance of the Enhanced product was generally consistent with that of the evaluation by Chan et al. (2018) who assessed the performance of the Enhanced products for the period April 1, 2015 to October 30, 2016 using in situ data from the SMAP mission core validation sites including Yanco. Chan et al. (2018) reported on the similarity between the performance of Enhanced products and that of SMAP passive soil moisture products. Based on their analysis, the SMAP EnhancedD data attained a mean $R^{2}$ of 0.92 (correlation coefficient/ $R=0.96$ ), mean RMSD of $0.048 \mathrm{~m}^{3} \mathrm{~m}^{-3}$ and mean bias of $0.02 \mathrm{~m}^{3} \mathrm{~m}^{-3}$ with in situ stations over the Yanco region. Li et al. (2018) evaluated the accuracy of the SMAP EnhancedD against two ground-based soil moisture and temperature monitoring networks located in the Tibetan Plateau, likewise reported on the reliability of the SMAP EnhancedD products in capturing the temporal variations of soil moisture. Li et al. (2018) reported small values of ubRMSE $\left(0.055-0.059 \mathrm{~m}^{3} \mathrm{~m}^{-3}\right)$ and high temporal correlation coefficients $(0.64-0.88)$ for Enhanced Products.

Similar to slope analysis for products at $1 \mathrm{~km}$, there was no substantial statistical difference between the mean slope values for products at $9 \mathrm{~km}$; with the range of mean slope being between 0.9 and 1.4. A slope larger than 1 could be attributed to the difference between the sensing depth of downscaled products (varying between 0 and $5 \mathrm{~cm}$ ) and that of in situ measurements being $0-5 \mathrm{~cm}$. 
An unequal number of soil moisture values were analysed for the different products included in the temporal analysis against the OzNet stations, due to the availability of product retrievals.

This may raise a concern about the impact of the unequal number of data used in the estimation of statistical metrics, and thus the findings from the analysis. Consequently, the temporal analysis was also conducted for a consistent number of data by using only observations on the same dates (eight days only). This included comparison of SMAP EnhancedD, SMAP SFIM, SMAP PassiveD, SMOS PassiveD, SMAP VTCI and SMOS VTCI against the OzNet measurements. Findings from this analysis were consistent with the earlier results. However, the statistical metrics of the eight days only scenario were deteriorated compared to those summarized in Figure 9. Still, the SMAP VTCI at both 1 and $9 \mathrm{~km}$ were found to have the best performance. For the comparisons conducted at $1 \mathrm{~km}$, the SMAP PassiveD followed closely the SMAP VTCI. Results obtained from the analysis of products at $9 \mathrm{~km}$ revealed that the performance of SMAP VTCI was followed by that of the SMAP EnhancedD and SMAP PassiveD.

\section{General results}

In the case of temporal analysis of downscaled products at $9 \mathrm{~km}$ against OzNet (Figure 13), SMAP EnhancedA and EnhancedD products were generally superior to other downscaled products. Both reached the highest temporal correlation with OzNet and had the lowest bias. SMAP VTCI at $1 \mathrm{~km}$ resolution also showed superiority to the remaining downscaled products at 1 $\mathrm{km}$.

\subsection{Temporal analysis against airborne PLMR soil moisture}

\section{Evaluation of products at $1 \mathrm{~km}$}

The temporal analysis of products was also carried out against the entire airborne PLMR soil moisture maps captured over the SMAPEx-4 and -5 airborne field campaigns. A summary of 


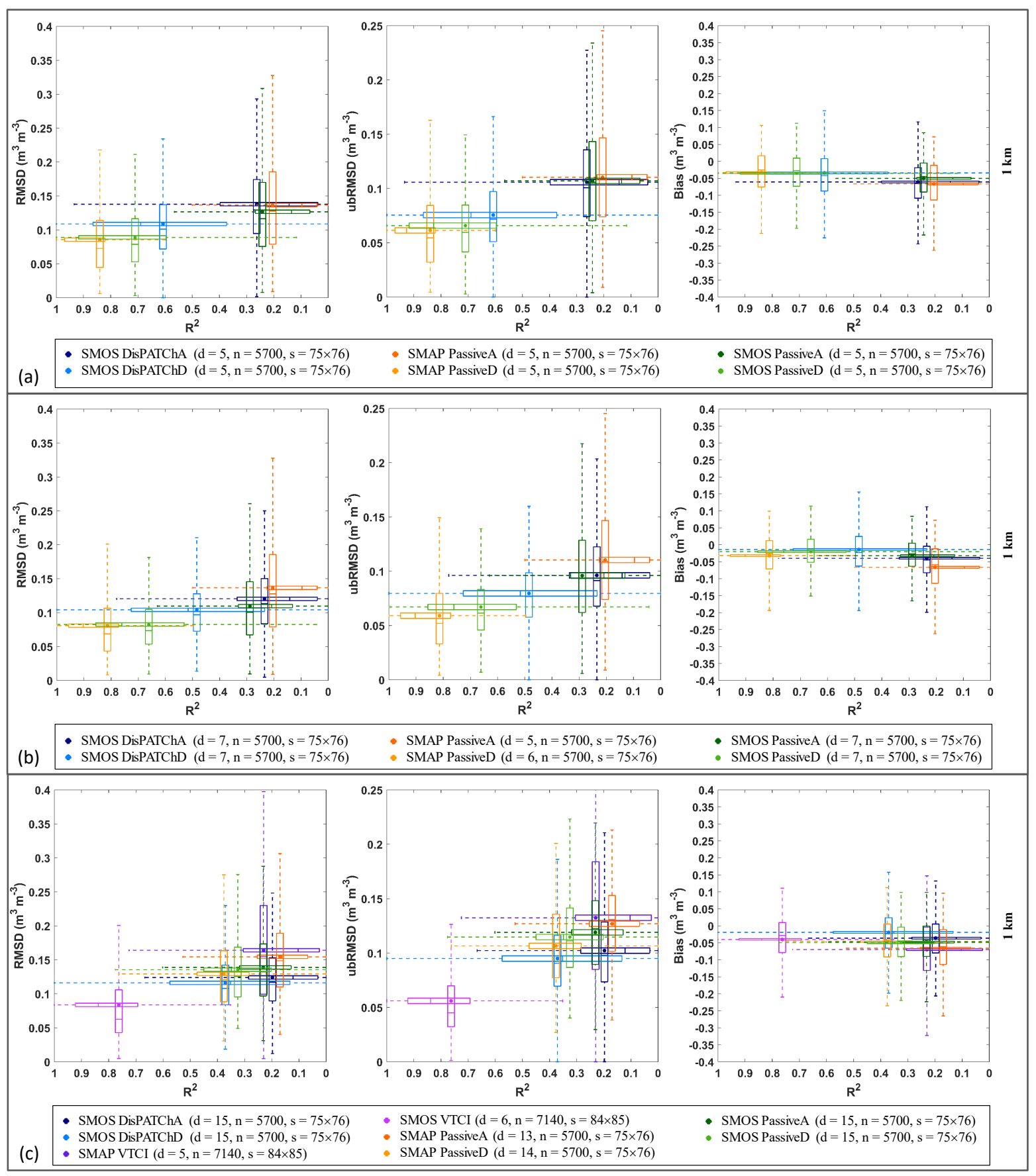

Figure 10: As for Figure 9 but for the comparison against airborne PLMR soil moisture at $1 \mathrm{~km}$ in which analysis was carried out for all the pixels covering the study area. These results are from different scenarios including: a) the equal number of downscaled products captured during SMAPEx-4, b) all available products during the SMAPEx-4, and c) products captured over the entire SMAPEx-4 and -5 airborne field campaigns' period. Here s stands for the dimension of analysis area arranged in row $\times$ column. Note: the performance analysis of the VTCI-based products was not possible for the SMAPEx-4 period as only one SMOS VTCI and two SMAP VTCI soil moisture maps were available. 


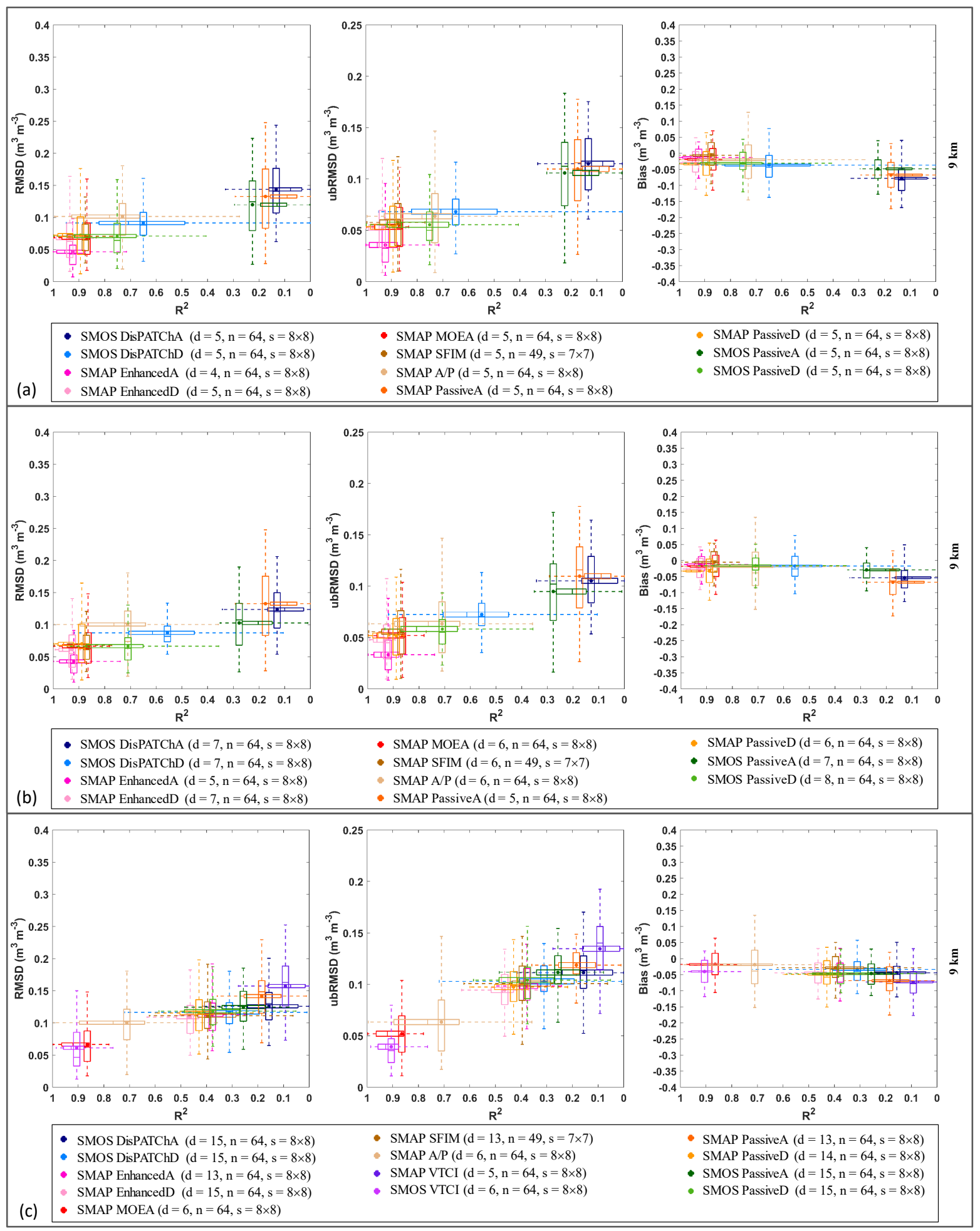

Figure 11: As for Figure 10 but for the comparison against airborne PLMR soil moisture at 9 $\mathrm{km}$.

product accuracy statistics at 1 and $9 \mathrm{~km}$ resolution are presented as boxplots in Figures 10 and

11, respectively. When the same number of downscaled and non-downscaled soil moisture maps 
at $1 \mathrm{~km}$ (Figure 10-a) were evaluated, descending SMAP and SMOS coarse passive products showed superiority in terms of accuracy when contrasted with the downscaled products, having a mean $\mathrm{R}^{2} \geq 0.6$ and mean RMSD of $\sim 0.09 \mathrm{~m}^{3} \mathrm{~m}^{-3}$. The SMOS DisPATChD maintained a similar accuracy to that of SMOS PassiveD, and performed the best among the downscaled products. Generally, all products underestimated the airborne PLMR soil moisture; with the underestimation being greater in the SMAP PassiveA and SMOS DisPATChA.

For the comparison against SMAPEx-4 and -5 airborne field campaigns (Figure 10-c), SMOS VTCI at $1 \mathrm{~km}$ performed the best with $\mathrm{R}^{2}$ of 0.76 , RMSD of $0.084 \mathrm{~m}^{3} \mathrm{~m}^{-3}$ and ubRMSD of $0.056 \mathrm{~m}^{3} \mathrm{~m}^{-3}$, which were better statistical metrics than for the other products. This was followed by the SMOS DisPATChD and SMAP PassiveD products which performed similarly; with a mean $\mathrm{R}^{2}$ close to 0.4 , mean RMSD of about $0.12 \mathrm{~m}^{3} \mathrm{~m}^{-3}$ and mean bias between 0 and $-0.05 \mathrm{~m}^{3} \mathrm{~m}^{-3}$. It is to be noted that the maximum $\mathrm{R}^{2}$ for both SMOS VTCI and DisPATChD was equal to 1 , while other products could not reach this high level of temporal agreement with airborne PLMR soil moisture. The slope of the linear regression defined between downscaled products and PLMR soil moisture maps showed dependency to $\mathrm{R}^{2}$. As anticipated, the slope values were small (close to zero) for products that had low $\mathrm{R}^{2}$. The slope was mainly explained by the correlation, knowing that slope equals to (correlation $) \times($ standard deviation of downscaled products/standard deviation of reference data). Therefore, the standard deviation of downscaled products was rather similar across all products. Comparison of SMOS VTCI and SMOS DisPATCh as optical-based products has also been conducted for the SMAPEx-4 and -5 airborne field campaigns, by choosing the same dates. Based on this comparison, the performance of DisPATCh and VTCI was quite comparable.

\section{Evaluation of products at $9 \mathrm{~km}$}

At $9 \mathrm{~km}$ resolution for the scenario in which the same number of soil moisture maps were evaluated (Figure 11-a), the SMAP EnhansedA and EnhancedD products with average $\mathrm{R}^{2}$ of 0.92 
and 0.94 , respectively, surpassed the other downscaled soil moisture products in capturing the temporal evolution of airborne soil moisture estimates, followed by SMAP PassiveD, SFIM and MOEA. The SMOS PassiveD and SMAP A/P products also showed a good performance with $\mathrm{R}^{2}$ of 0.75 for the first and 0.73 for the later. The SMAP PassiveD without being downscaled was amongst the best results and yielded an $\mathrm{R}^{2}$ of 0.89 and ubRMSD of $0.054 \mathrm{~m}^{3} \mathrm{~m}^{-3}$. Nevertheless, the SMAP EnhancedA was found to have the best agreement with airborne PLMR soil moisture. The SMAP EnhancedA not only had a high coefficient of determination but also low RMSD and/or ubRMSD. The DisPATChA at $9 \mathrm{~km}$ - retrieved from an optical-based downscaling technique - had the lowest agreement with airborne PLMR soil moisture. This is unlike the DisPATChD which was shown to have a moderate performance with $\mathrm{R}^{2}$ of 0.75 . The DisPATChD yielded on average similar performance to the SMOS PassiveD. While it did not improve nor maintain the accuracy of SMOS PassiveD in terms of RMSD and ubRMSD, it deteriorated the $\mathrm{R}^{2}$ and bias relative to SMOS PassiveD. Nevertheless, the $\mathrm{R}^{2}$ of SMOS PassiveD was not significantly above that of DisPATChD. These findings are in agreement with those obtained from evaluation of all available soil moisture products during the SMAPEx-4 (Figure $11-b)$

For the comparison against SMAPEx-4 and -5 airborne field campaigns (Figure 11-c), SMOS VTCI at $9 \mathrm{~km}$ performed the best with a mean $\mathrm{R}^{2}$ of 0.91 , mean bias of $-0.04 \mathrm{~m}^{3} \mathrm{~m}^{-3}$, mean RMSD of $0.061 \mathrm{~m}^{3} \mathrm{~m}^{-3}$, and mean ubRMSD of $0.039 \mathrm{~m}^{3} \mathrm{~m}^{-3}$ followed by SMAP MOEA and A/P, which were only available for the SMAPEx-4 period. The remaining products, with the exception of the SMAP VTCI, SMOS DisPATChA and SMAP PassiveA, had similar performance with mean $\mathrm{R}^{2}$ between 0.2 and 0.5 and varying RMSD between 0.1 and $0.13 \mathrm{~m}^{3} \mathrm{~m}^{-3}$.

\section{Seasonal performance of products at $1 \mathrm{~km}$}

In order to assess the seasonal impact on the performance of products at $1 \mathrm{~km}$, the temporal analysis of products was also carried out for the SMAPEx-5 airborne field campaign conducted 
in the austral spring. During the SMAPEx-5 with wet soils, the products again underestimated the airborne PLMR soil moisture, being even more severe than for SMAPEx-4. This underestimation could be the result of standing water in some fields and the denser vegetation cover in cropping areas during SMAPEx-5. The performance of SMOS DisPATChD, SMAP EnhancedD, SMAP EnhancedA and SMAP PassiveD during SMAPEx-5 showed a minor difference over their performance during SMAPEx- 4 in terms of $\mathrm{R}^{2}$ and ubRMSD. With the exception of SMOS PassiveD, whereby $\mathrm{R}^{2}$ decreased marginally from 0.66 (SMAPEx-4) to 0.57 (SMAPEx5 ), the $\mathrm{R}^{2}$ of remaining products during SMAPEx- 5 increased by more than 0.5 compared to that of SMAPEx-4. The SMAP PassiveA products experienced the largest increase (0.68) in terms of $\mathrm{R}^{2}$ and had the lowest agreement with SMAPEx-4 PLMR soil moisture. More explicit spatial and temporal patterns of soil moisture were observed in the PLMR derived maps during the SMAPEx-5 than the SMAPEx-4 airborne field campaign, as shown in Figure 6 and 7. Therefore, it was expected that the downscaled products would best capture the explicit spatial and temporal variability of soil moisture during the SMAPEx-5 airborne field campaign. Results from the comparison of SMOS VTCI and SMOS DisPATCh on the same dates during the SMAPEx-5 airborne field campaign revealed a similarity of DisPATCh and VTCI in terms of performance.

For the comparison against SMAPEx-5 airborne field campaign data, with the exception of SMOS PassiveD and DisPATChD with $\mathrm{R}^{2}$ less than 0.6, the remaining products were found to have an $\mathrm{R}^{2}$ greater than 0.75 . The SMOS DisPATChA had a reasonable performance with an $\mathrm{R}^{2}$ of 0.77 , a lower bias $\left(-0.033 \mathrm{~m}^{3} \mathrm{~m}^{-3}\right)$ and a lower ubRMSD $\left(0.044 \mathrm{~m}^{3} \mathrm{~m}^{-3}\right)$ than other products. This is unlike the SMOS VTCI, SMAP VTCI, SMAP PassiveA, SMAP PassiveD, and SMOS PassiveA, which with $\mathrm{R}^{2} \geq 0.85$ could not meet the accuracy requirements in terms of bias and RMSD. For instance, the SMOS VTCI had the largest bias equal to $-0.115 \mathrm{~m}^{3} \mathrm{~m}^{-3}$ on average and the largest RMSD equal to $0.143 \mathrm{~m}^{3} \mathrm{~m}^{-3}$ on average. 


\section{Seasonal performance of products at $9 \mathrm{~km}$}

The seasonal performance assessment was also carried out for the products at $9 \mathrm{~km}$. Based on this comparison, with the exception of SMOS PassiveD, SMOS DisPATChA and DisPATChD, the remaining products were superior with an $\mathrm{R}^{2} \geq 0.9$. This is not in line with the findings from the SMAPEx-4 in which SMOS PassiveA, SMOS DisPATChA and SMAP PassiveA had an $\mathrm{R}^{2}$ less than 0.3. Generally, the variation of RMSD, ubRMSD, and bias obtained from evaluation of $9 \mathrm{~km}$ products during the SMAPEx-5 was found to be smaller than that of products at $1 \mathrm{~km}$. Still, the average of obtained statistical metrics for $9 \mathrm{~km}$ products was quite similar to that of products at $1 \mathrm{~km}$.

Generally, a comparison of the temporal performance of DisPATCh products against airborne PLMR soil moisture showed that the accuracy of DisPATCh products was noticeably affected by that of the SMOS Passive products. While DisPATCh products were not superior to SMOS Passive products in terms of $\mathrm{R}^{2}$, the DisPATCh products were shown to mimic the SMOS Passive $\mathrm{R}^{2}$. For example, the SMOS PassiveA and SMOS PassiveD at $9 \mathrm{~km}$ had an average $\mathrm{R}^{2}$ of 0.9 and 0.63 , respectively, during the SMAPEx-5, with DisPATChA and DisPATChD showing an average $\mathrm{R}^{2}$ of 0.8 and 0.5 for the former and latter. Results herein have also shown that DisPATCh products had a higher RMSD/ubRMSD than SMOS Passive products during SMAPEx-4, which is opposite to the results obtained for the SMAPEx-5 period. During SMAPEx-5 the RMSD of DisPATCh products were slightly lower than those of the SMOS Passive products.

\section{General results}

Analysis of downscaled products against airborne PLMR soil moisture maps revealed the superiority of the oversampling-based technique in terms of delivering more frequent and accurate downscaled products than the radar-, optical- and radiometer-based techniques. The SMAP Enhanced products not only had better performance and availability, but also showed improve- 
ment over coarse SMAP radiometer only soil moisture products in terms of accuracy and spatial scale.

\section{Spatial analysis against airborne PLMR soil moisture}

Spatial analysis of soil moisture products was carried out against airborne PLMR soil moisture maps covering the entire study area during the SMAPEx-4 and -5 airborne field campaigns. This spatial analysis involved evaluation of the daily maps of soil moisture estimates against the corresponding airborne PLMR maps in the same scenarios as in the temporal analysis. A summary of the spatial accuracy statistics of products at 1 and $9 \mathrm{~km}$ are presented as boxplots in Figures 12 and 13, respectively.

\section{Evaluation of products at $1 \mathrm{~km}$}

When downscaled soil moisture maps at $1 \mathrm{~km}$ were evaluated (Figure 12), they showed low spatial correlation, denoted by $\mathrm{R}^{2}$, with airborne PLMR maps. Such a low spatial correlation was followed by low linear regression slope. In the spatial analysis, the spatial correlation was very low for all products, with the slope mainly determined by the standard deviation of downscaled products in space. Furthermore, they underestimated the variability of the PLMR soil moisture with the range of average bias between -0.016 and $-0.075 \mathrm{~m}^{3} \mathrm{~m}^{-3}$. For the scenarios including: i) evaluation of the same number of products (Figure 12-a) and ii) evaluation of products during the SMAPEx-4 (Figure 12-b), the products had a mean $\mathrm{R}^{2}$ of less than 0.2 and the range of mean RMSD between 0.083 and $0.146 \mathrm{~m}^{3} \mathrm{~m}^{-3}$. These results in general are not much different from those of comparisons against SMAPEx-4 and -5 airborne field campaigns (Figure 12-c). However, results in Figure 12-c showed closer resemblance in the performance of products compared to Figure 12-a and b. 


\section{Evaluation of products at $9 \mathrm{~km}$}

In the case of spatial pattern analysis of products at $9 \mathrm{~km}$ (Figure 13), generally, SMAP EnhancedA and EnhancedD products were superior to other products. Both reached the highest spatial correlation with airborne PLMR soil moisture and had the lowest bias. Nevertheless, the SMAP Enhanced products had mean $\mathrm{R}^{2}$ less than 0.5 and mean bias larger than $0.04 \mathrm{~m}^{3}$ $\mathrm{m}^{-3}$. In addition, the slope of linear regression between SMAP Enhanced products and PLMR soil moisture was close to 0.1 . The slope was mainly determined by the standard deviation of downscaled products in space, which is expected to be lower for coarser/lower resolutions. The SMAP A/P showed the highest variability in terms of slope range, and SMAP EnhancedA was one of the products with the lowest variability. Apart from the Enhanced products, the SFIM performance was shown to be one of the best during the short SMAPEx-4 period.

\section{Seasonal performance of products at $1 \mathrm{~km}$}

Comparison of the performance of products at $1 \mathrm{~km}$ during the SMAPEx-5 (austral spring) against that of products during the SMAPEx-4 (austral autumn) showed that there was no noticeable seasonal impact on the spatial performance of products. None of the products at $1 \mathrm{~km}$ could capture the spatial pattern of PLMR soil moisture with high correlation and low RMSD. Agreeing with findings from the evaluation of products during the SMAPEx-4 period, the mean $\mathrm{R}^{2}$ of products was generally less than 0.1 and mean RMSD was higher than $0.09 \mathrm{~m}^{3}$ $\mathrm{m}^{-3}$ for SMAPEx-5. Regardless of season, there was an underestimation of PLMR soil moisture by products with a more noticeable error in the SMAPEx-5 period.

\section{Seasonal performance of products at $9 \mathrm{~km}$}

In contrast to the seasonal performance of products at $1 \mathrm{~km}$, the seasonal impact on the spatial performance of products at $9 \mathrm{~km}$ was noticeable. Products at $9 \mathrm{~km}$ showed slightly better performance during SMAPEx-4 than during SMAPEx-5 when soils were wet. Comparison of 


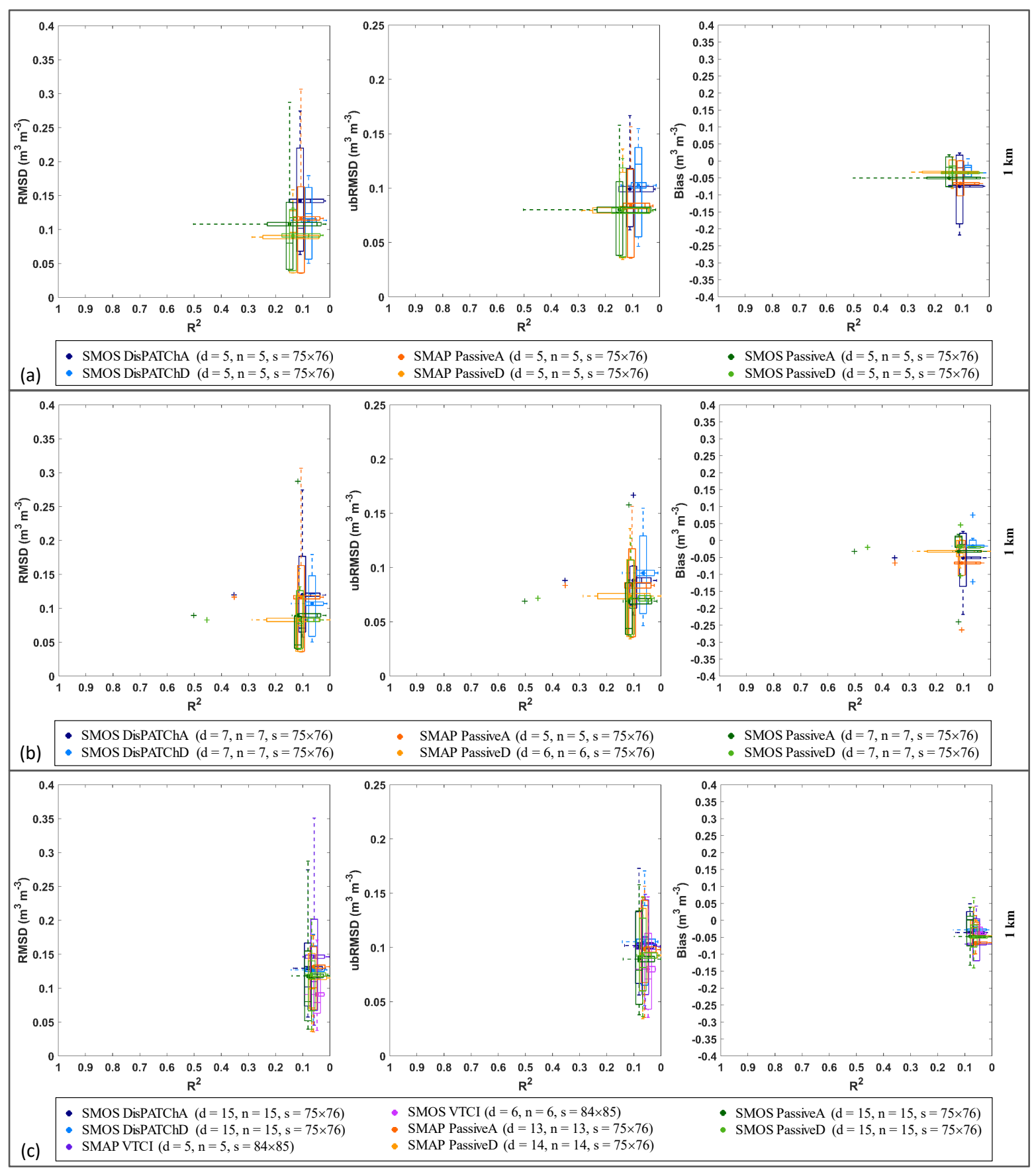

Figure 12: Summary of results obtained from spatial analysis of soil moisture products at 1 $\mathrm{km}$ against airborne PLMR soil moisture in which analysis was carried out for all the pixels covering the study area. These results are from different scenarios including: a) the equal number of downscaled products captured during SMAPEx-4, b) all available products during the SMAPEx-4, and c) products captured over the entire SMAPEx-4 and -5 airborne field campaigns' period.

the correlation of products with PLMR soil moisture during SMAPEx-5 with that of products during SMAPEx-4 showed a reduction of $\mathrm{R}^{2}$ for SMAPEx-5, which was more pronounced for the SMAP SFIM. The SMAP SFIM was among products with the best performance during 
SMAPEx-4, but among those with the poorest performance during SMAPEx-5. The SMAP SFIM experienced a decrease in $\mathrm{R}^{2}$ from 0.33 in SMAPEx- 4 to 0.14 in SMAPEx-5 and increase of RMSD from 0.062 to $0.093 \mathrm{~m}^{3} \mathrm{~m}^{-3}$. Although the performance of SMAP EnhancedA was slightly poorer during SMAPEx-5 than SMAPEx-4, it still ranked the best with $\mathrm{R}^{2}$ of 0.18 , RMSD of $0.089 \mathrm{~m}^{3} \mathrm{~m}^{-3}$ and ubRMSD of $0.055 \mathrm{~m}^{3} \mathrm{~m}^{-3}$.

\section{General results}

Based on the results, none of the downscaled products could capture the spatial variability of the PLMR soil moisture maps. Products at both 1 and $9 \mathrm{~km}$ showed low spatial correlation with airborne PLMR maps, denoted by $\mathrm{R}^{2}$ values less than 0.5 . However, products at $1 \mathrm{~km}$ had a lower spatial correlation than the products at $9 \mathrm{~km}$, with $\mathrm{R}^{2}$ values of $\sim 0.1$. While none of these methods met the accuracy expectations, the slightly better results at $9 \mathrm{~km}$ were expected, being an artefact of undertaking the evaluation at larger spatial scales where the high spatial variability is smoothed by the averaging processes.

Superiority of the oversampling-based technique to the radar-, optical- and radiometerbased techniques, in capturing spatial variability of airborne PLMR soil moisture, was revealed based on findings from spatial analysis. Nevertheless, the oversampling-based products did not indicate a strong correlation with the airborne PLMR spatial pattern. The superiority of the oversampling-based product relative to others was not limited to just the spatial patterns provided by airborne PLMR soil moisture maps; temporal evaluation against the in situ soil moisture measurements and airborne PLMR soil moisture estimates also revealed superiority of the oversampling-based products. For both of the temporal analyses, oversampling-based products had a low RMSD/ubRMSD and high $\mathrm{R}^{2}$ values. Availability of the oversamplingbased products under all-weather conditions is another factor supporting their adoption for applications. 


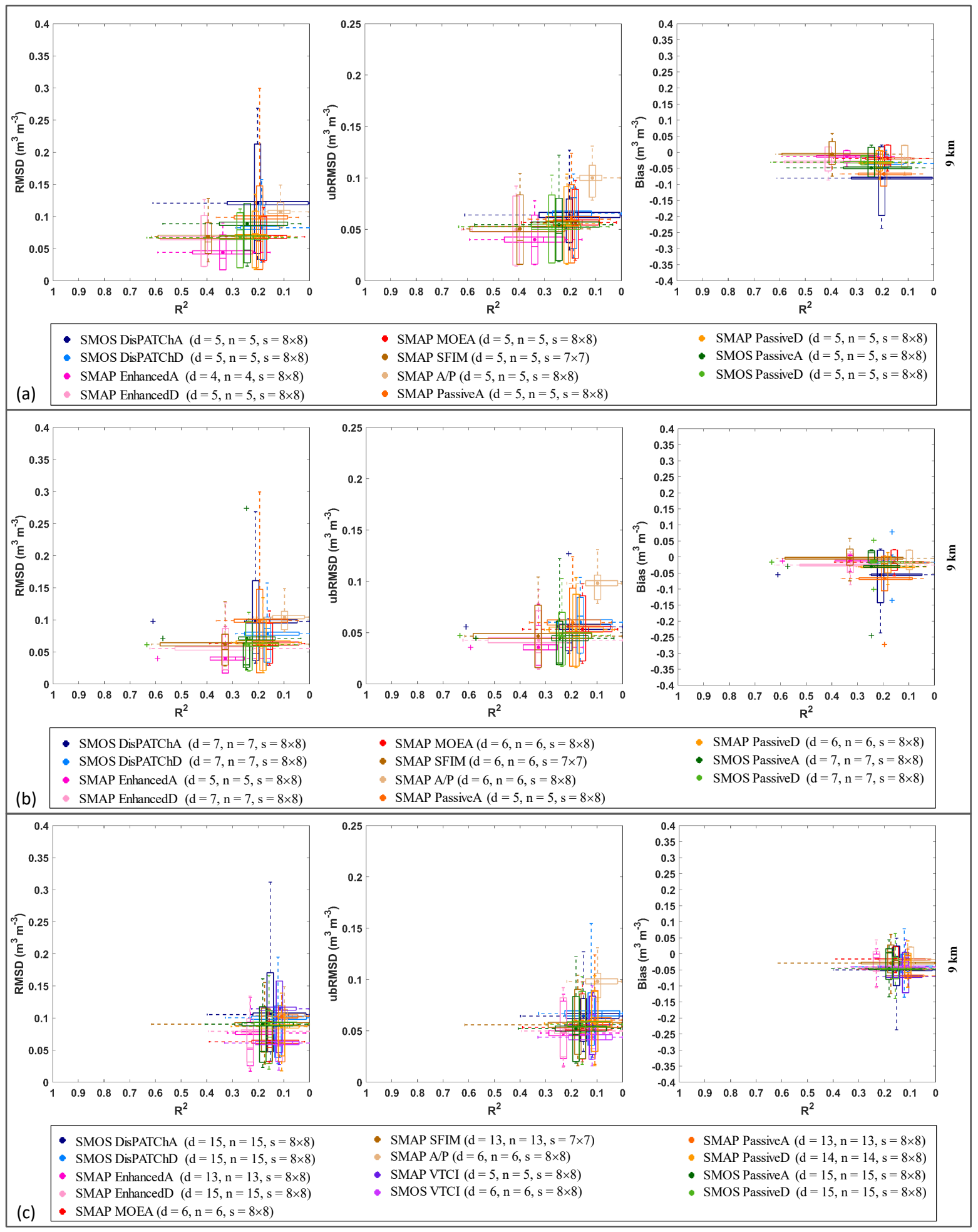

Figure 13: As for Figure 12 but for the spatial analysis at $9 \mathrm{~km}$. 
This paper has rigorously assessed the performance of a variety of available downscaled soil moisture products at resolutions between 1 and $10 \mathrm{~km}$, to find approach(es) that is(are) applicable for multi-sensor soil moisture retrieval from the SMAP and SMOS. This assessment involved comprehensive inter-comparison of downscaled products, including radar-, optical-, radiometer- and oversampling-based retrievals against in situ and airborne reference data for a typical Australian landscape and climate. The performance of the original coarse radiometer only products including SMAP and SMOS was analyzed to understand the extent of improvement of their respective downscaled products in terms of accuracy and capability of capturing the spatio-temporal variability of soil moisture relative to assuming a uniform spatial field. A summary of accuracy statistics of the downscaled and non-downscaled products at $9 \mathrm{~km}$, evaluated against the airborne PLMR soil moisture during SMAPEx-4 and -5 , and OzNet in situ soil moisture measurements is provided in Table 2. Based on Table 2, none of the products at $9 \mathrm{~km}$ could deliver soil moisture estimates at an accuracy of $0.04 \mathrm{~m}^{3} \mathrm{~m}^{-3}$, being the accuracy requirement suggested for a wide range of soil moisture applications over areas with vegetation water content of less than $5 \mathrm{~kg} \cdot \mathrm{m}^{-2}$ (Entekhabi et al., 2008).

Based on the results, downscaled products showed a range of performance against different reference data sets and under differing spatial scale, weather and climate condition. This variation of performance between downscaled products could be influenced by the nature of utilized ancillary data for downscaling purpose. For example, in Figure 6 and 7 the optical-based products could not retrieve consistent time series of soil moisture maps under cloudy skies as optical observations are not captured under cloud coverage. This shortcoming reduces the functionality of optical-based techniques while the high temporal and spatial resolution of optical observations make them a promising ancillary data for soil moisture downscaling. Studies such as Zhao and Li (2013), Peng et al. (2015), Piles et al. (2016), and Sabaghy et al. (2018) have 


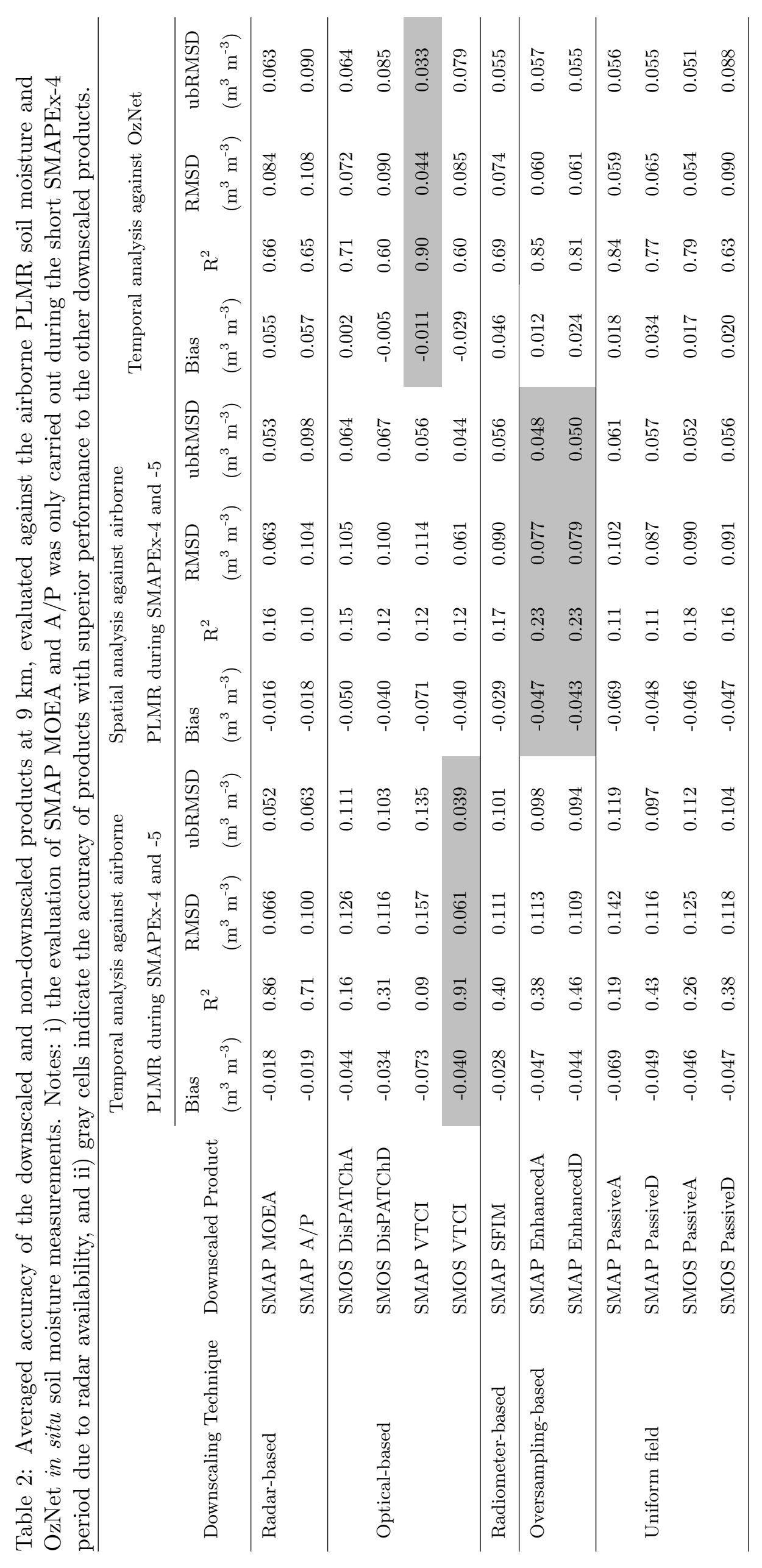


suggested the use of geostationary based optical observations, instead of the optical imagery captured by polar orbiting counterparts, to overcome this issue. The geostationary sensors provide more frequent acquisitions and thus an opportunity for more cloud-free observations. Furthermore, multi-sensor data fusion techniques could be employed as an alternative to the use of geostationary based optical observations, in order to generate continuous time series of cloud-free optical imageries (e.g. Long et al., 2019).

Unlike optical-based products, radar-, radiometer-, and oversampling-based downscaled soil moisture maps were available regardless of meteorological conditions. Oversampling-based products retrieved from optimal interpolation theory, which provides the closest observation to what could be measured by the radiometric instrument at the interpolation point, has the added advantage of not needing concurrent data from other sensors. This factor prevents data loss due to unavailability of required ancillary data for disaggregation. The lack of access to concurrent radar and radiometer observations that have the same temporal repeat is the main factor that limits the application of the radar-based downscaling techniques.

The oversampling-based soil moisture products (SMAP EnhancedA and SMAP EnhancedD) best captured the temporal and spatial variability of soil moisture overall, though the SMAP MOEA and A/P had the better temporal agreement with PLMR during the short SMAPEx-4 period. This superiority may lie in the characteristic of the L-band radiometer and radar data used for their soil moisture disaggregation. Especially, the oversampling-based soil moisture products with their disaggregation procedure based on the use of SMAP L-band radiometer imageries that are less affected by vegetation cover, surface roughness and meteorology condition. The summary of accuracy statistics, in the review of temporal analysis of different downscaling techniques displayed in Figure 8 of Sabaghy et al. (2018), indicated that the radarbased technique was expected to deliver more accurate downscaled soil moisture products than optical-based techniques, with radar having been previously shown to have a greater sensitivity to soil moisture dynamics than optical observation and with a direct relation to soil moisture 
dynamics. Nevertheless, in this study the temporal analysis of products against the OzNet ground-based soil moisture measurements revealed that optical-based products (SMAP VTCI at $9 \mathrm{~km}$ ) performed the best, followed by the oversampling-based product (SMAP EnhancedD). The radiometer-based products which had the poorest performance in the review by Sabaghy et al. (2018), herein showed reasonable performance, being slightly higher than that of radarbased products (SMAP A/P and MOEA). Moreover, the temporal analysis of products against the airborne PLMR soil moisture during SMAPEx-4 and -5 revealed that SMOS VTCI at $9 \mathrm{~km}$ performed the best, followed by the radar-based products (SMAP A/P and MOEA).

Differences observed between the temporal analysis of products against in situ and airborne soil moisture references suggest that relying only on in situ measurement is not appropriate for validation of soil moisture maps; basically in situ measurements are not necessarily a great indicator of soil moisture variation in space. Furthermore, in situ measurements are not consistent and have station-to-station bias variations (Colliander et al., 2017). In addition, Yee et al. (2016) recommended a need to identify the most representative station(s) based on evaluation against intensive soil moisture measurements to avoid biases in the in situ measurements due to station placement. While there are a few isolated locations where temporal evaluation was possible using stations, the aircraft with its full spatial coverage created the opportunity to look in detail at the spatial patterns.

Based on the temporal analysis of seasonal performance, the performance of SMOS PassiveA and DisPATChA products were noticeably affected by the season. The $9 \mathrm{~km}$ SMOS PassiveA and DisPATChA had mean $\mathrm{R}^{2}<0.3$ during SMAPEx- 4 and mean $\mathrm{R}^{2} \geq 0.8$ during SMAPEx5, while the average RMSD/ubRMSD and bias of these products was approximately the same for both campaigns. Merlin et al. (2012) previously reported a similar impact of seasonal variations on the accuracy of DisPATCh products in capturing the spatial dynamic of soil moisture but with better temporal correlation of DisPATCh products against reference soil moisture for summer (semi-arid climate) than winter (temperate climate). The downscaled 
DisPATCh products were derived using the evaporative efficiency as the main downscaling factor, which has a higher level of coupling with surface soil moisture for the semi-arid rather than temperate climate (e.g. Colliander et al., 2017; Merlin et al., 2012); with evsporation being the primary control on soil wetness in semi-arid conditions. Results herein have shown that the $\mathrm{R}^{2}$ of DisPATChD during semi-arid (SMAPEx-4, austral spring) and temperate climate (SMAPEx-5, austral autumn) remained the same. Conversely, results from the analysis of DisPATChA products agree with the results of Merlin et al. (2012), being that the $\mathrm{R}^{2}$ of DisPATChA for the semi-arid climate was significantly higher than that of DisPATChA for the temperate climate. In order to avoid such a reduction of DisPATCh performance for wet soil conditions, Djamai et al. (2015) have recommended the use of a non-linear relationship between soil moisture and soil evaporative efficiency instead of the linear one used herein.

Results also showed that the seasonal performance of DisPATCh products was similar to that of passive soil moisture estimates from which the DisPATCh products originated. These findings suggest that the performance of DisPATCh is heavily influenced by the performance of the original passive soil moisture estimates. Therefore, the uncertainty of the original passive soil moisture products is dictating the accuracy of DisPATCh. These findings are not consistent with findings from Merlin et al. (2012) and Colliander et al. (2017), that proposed the coupling between soil moisture and evaporative efficiency as the main factor controlling the accuracy of DisPATCh products. Improvement of the accuracy of passive coarse soil moisture products is therefore another requirement for improvement of DisPATCh products.

Based on the spatial analysis of seasonal performance, products at $1 \mathrm{~km}$ had similar performance for SMAPEx-4 and SMAPEx-5 regardless of season. These results are contrasted against those obtained from spatial analysis of products at $9 \mathrm{~km}$. In general, products at 9 $\mathrm{km}$ had slightly better performance during SMAPEx-4 than SMAPEx-5. The stark contrast of the performance of downscaled products during SMAPEx-4 and SMAPEx-5, was specifically introduced for SMAP SFIM products. Reduced sensitivity of high frequency radiometer obser- 
vations to soil moisture dynamics under increased vegetation cover and rainfall events during SMAPEx-5 could be the key factor in accuracy reduction of SMAP SFIM in temperate climate.

\section{Conclusion}

This paper has presented the first analysis of the alternative downscaled soil moisture products currently available against a common reference data set, to overview their applicability for the applications requiring soil moisture products at resolutions higher than $10 \mathrm{~km}$. While cloudy skies limit the application of optical-based downscaled products, the SMAP and SMOS VTCI as optical-based products had the highest level of temporal agreement with OzNet and airborne PLMR soil moisture, respectively. However, they could not meet the temporal requirements for applications. The use of geostationary based optical sensors which collect data at about 30 minute time intervals may help to overcome this shortcoming by increasing the chance of capturing cloud-free observations.

The oversampling-based soil moisture products (SMAP EnhancedA and SMAP EnhancedD)

best captured the temporal and spatial variability of soil moisture overall, though the SMAP MOEA and A/P had a better temporal agreement with PLMR during the short SMAPEx-4 period. The SMAP Enhanced products not only surpassed the other downscaled products in terms of performance and accuracy, but also in terms of availability under all-weather conditions and improvement of soil moisture retrieval over coarse passive microwave retrievals. Furthermore, the interpolation technique used for the Enhanced soil moisture production does not require any concurrent data from other satellites. However, the spatial resolution of the SMAP Enhanced products does not meet the requirements for application to agriculture and water resources management, which need a resolution of at least $1 \mathrm{~km}$.

The difference between temporal analysis of products against in situ and airborne soil moisture reference data sets also pointed to the fact that relying on in situ measurement alone is not appropriate for validation of soil moisture maps; basically in situ measurements that are 


\section{Acknowledgements}

This research was made possible through the financial support from an ARC Discovery Project (MoistureMonitor, DP140100572) and Infrastructure grant (LE0453434). Monash University is also acknowledged for its contribution towards a postgraduate scholarship for Sabah Sabaghy to pursue her PhD. Jian Peng was supported by the ESA SEOM project "Exploitation of S-1 for Surface Soil Moisture Retrieval at High Resolution" under Contract 4000118762/16/I-NB. 


\section{Appendix A}

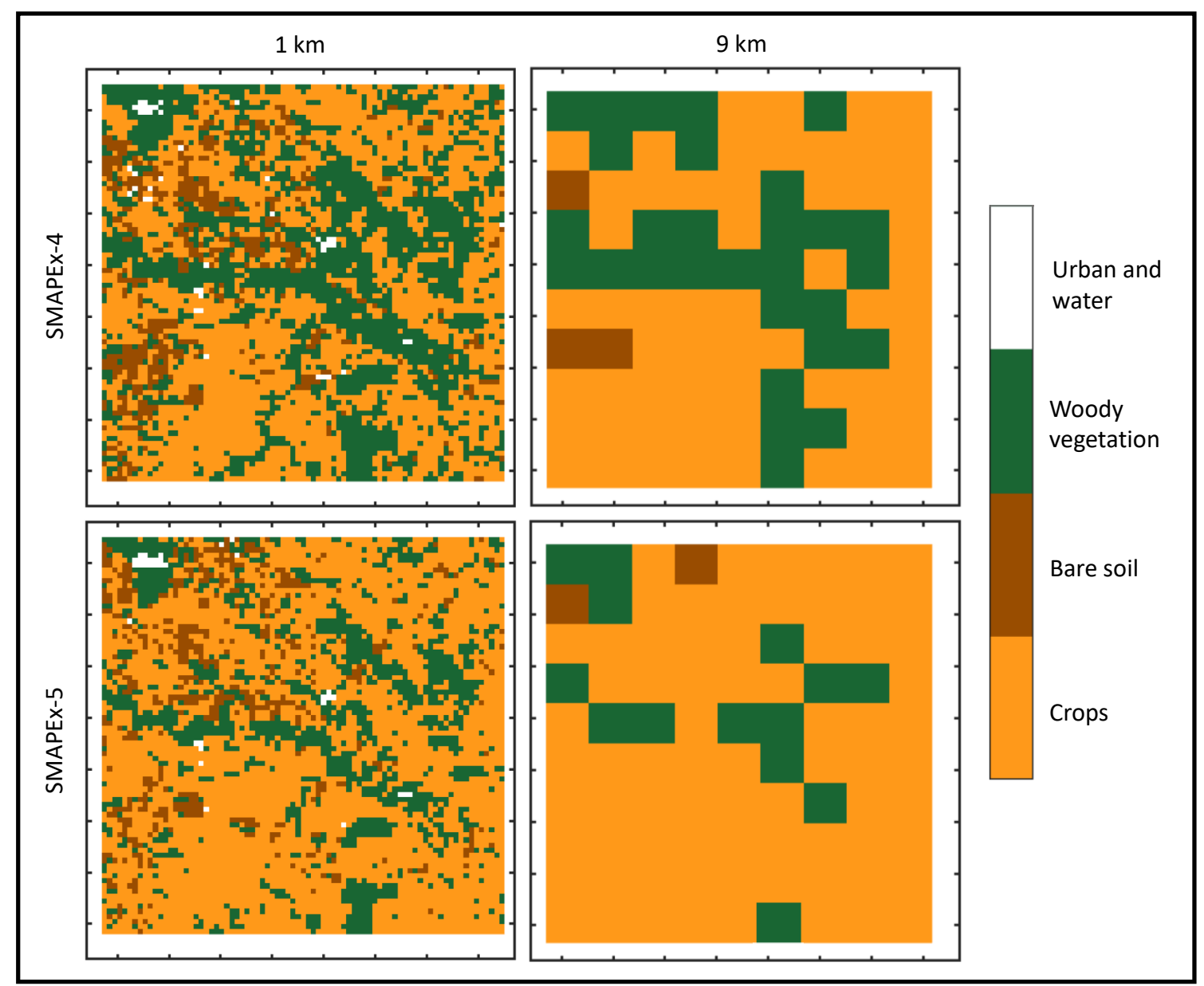

Figure A1: Land cover maps showing dominant vegetation cover at 1 and $9 \mathrm{~km}$ spatial resolution the same as that of downscaled soil moisture maps. 


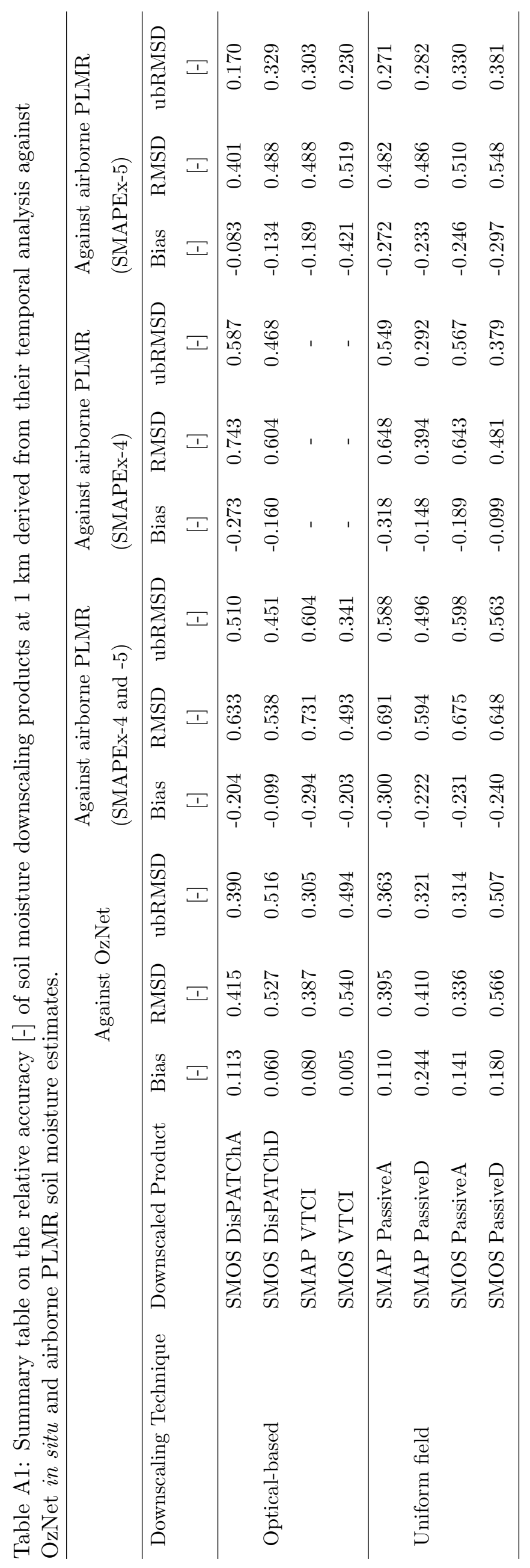




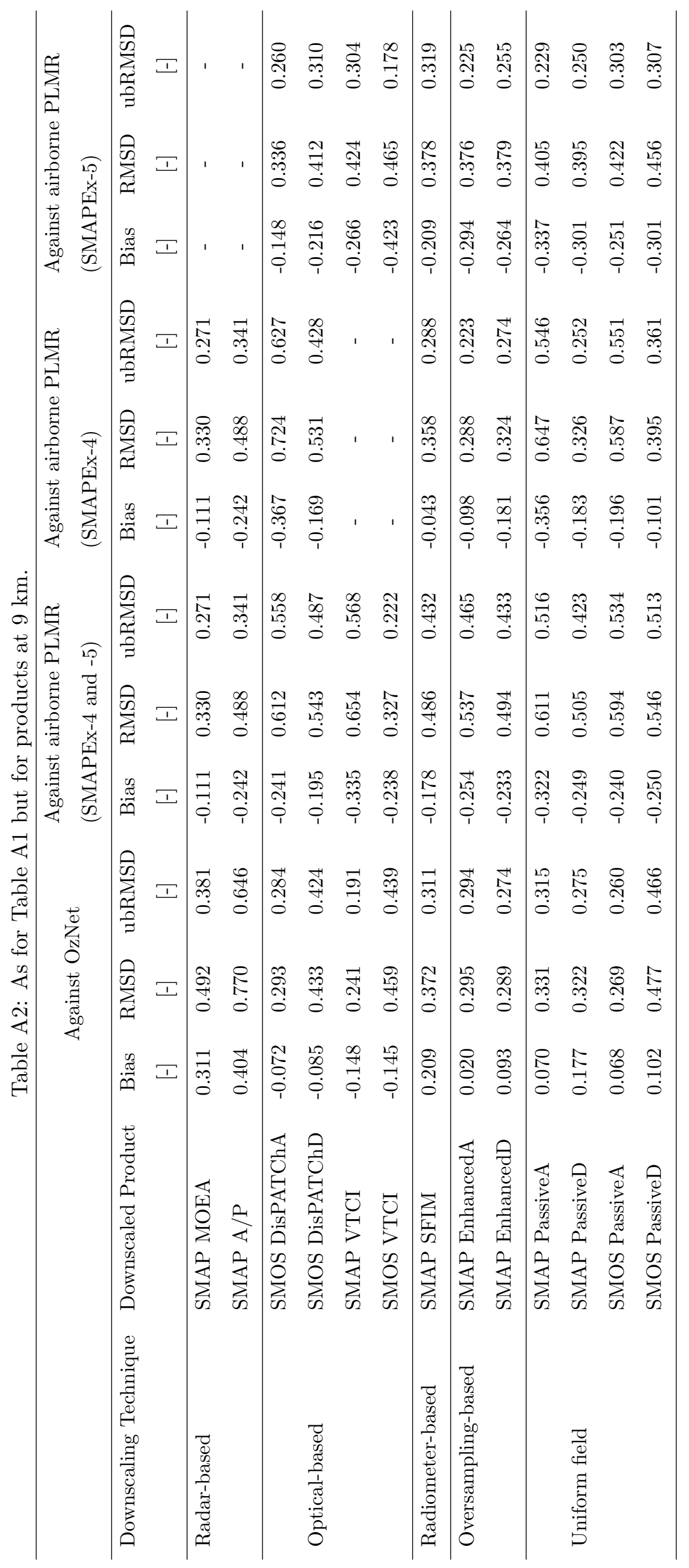




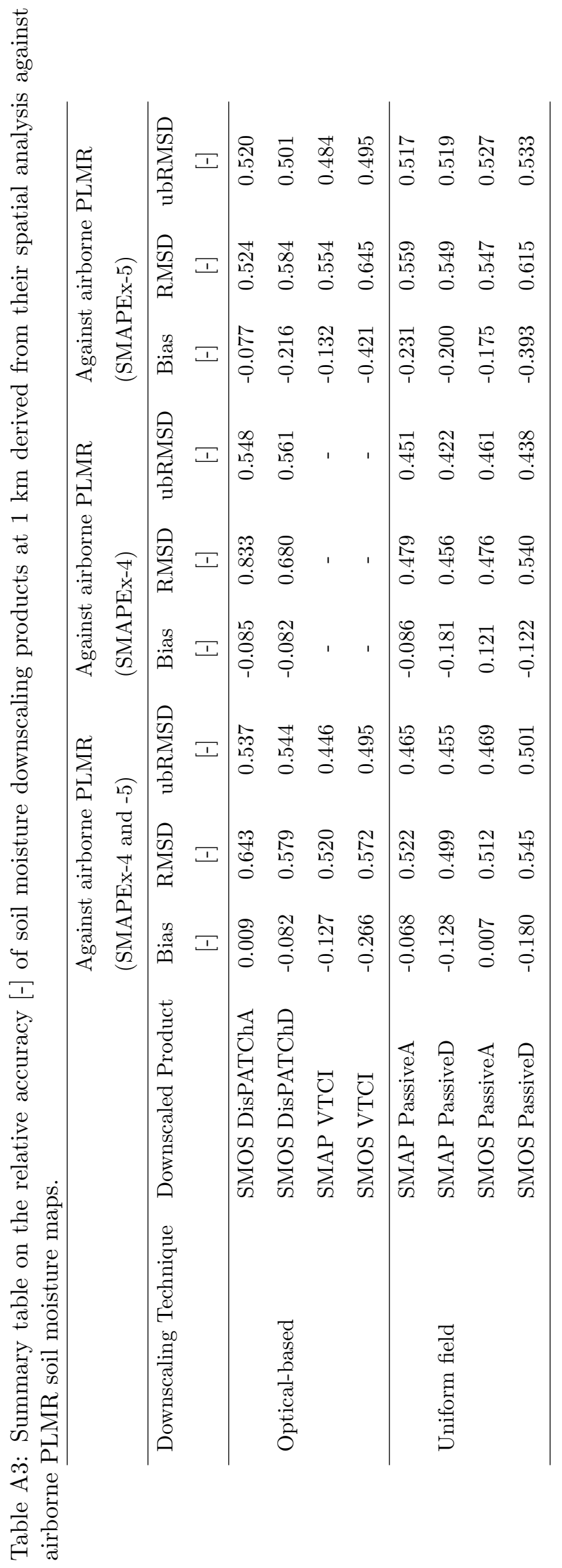




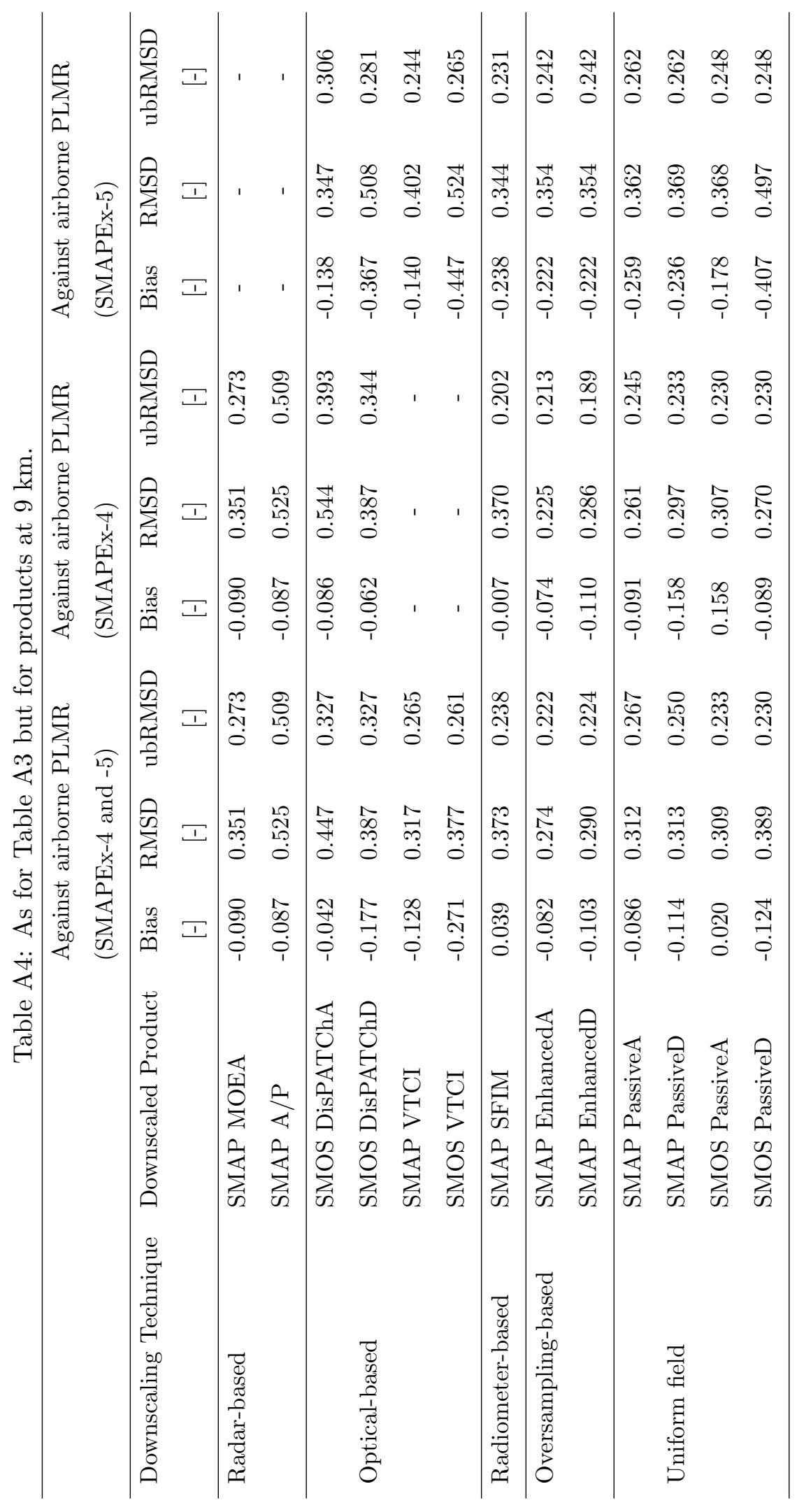




\section{References}

R. Akbar and M. Moghaddam. A combined active-passive soil moisture estimation algorithm with adaptive regularization in support of SMAP. IEEE Transactions on Geoscience and Remote Sensing, 53(6):3312-3324, 2015.

R. Akbar, S. Chan, N. Das, S. Kim, D. Entekhabi, and M. Moghaddam. A multi-objective optimization approach to combined radar-radiometer soil moisture estimation. In IEEE International Geoscience and Remote Sensing Symposium (IGARSS), pages 3074-3077, July 2016.

A. Al-Yaari, J.-P. Wigneron, W. Dorigo, A. Colliander, T. Pellarin, S. Hahn, A. Mialon, P. Richaume, R. Fernandez-Moran, L. Fan, Y. Kerr, and G. D. Lannoy. Assessment and inter-comparison of recently developed/reprocessed microwave satellite soil moisture products using ISMN ground-based measurements. Remote Sensing of Environment, 224:289 $303,2019$.

M. C. Anderson, J. M. Norman, J. R. Mecikalski, J. A. Otkin, and W. P. Kustas. A climatological study of evapotranspiration and moisture stress across the continental united states based on thermal remote sensing: 1. model formulation. Journal of Geophysical Research: Atmospheres, 112(D10), 2007.

G. Backus and F. Gilbert. Uniqueness in the inversion of inaccurate gross earth data. Philosophical Transactions of the Royal Society of London A: Mathematical, Physical and Engineering Sciences, 266(1173):123-192, 1970.

G. E. Backus and J. Gilbert. Numerical applications of a formalism for geophysical inverse problems. Geophysical Journal International, 13(1-3):247-276, 1967.

R. Bindlish, T. Jackson, M. Cosh, S. Ruijing, S. Yueh, and S. Dinardo. Combined passive and 
active soil moisture observations during clasic. In IEEE International Geoscience and Remote Sensing Symposium (IGARSS), volume 2, pages II-237-II-240, 2008.

J. D. Bolten, W. T. Crow, X. Zhan, T. J. Jackson, and C. A. Reynolds. Evaluating the utility of remotely sensed soil moisture retrievals for operational agricultural drought monitoring. IEEE Journal of Selected Topics in Applied Earth Observations and Remote Sensing, 3(1): 57-66, 2010.

Bureau of Meterology. Climate statistics for Australian locations. Australian Government, 2018. URL http://www.bom.gov.au/climate/data/.

T. N. Carlson, R. R. Gillies, and E. M. Perry. A method to make use of thermal infrared temperature and ndvi measurements to infer surface soil water content and fractional vegetation cover. Remote Sensing Reviews, 9(1-2):161-173, 1994.

S. Chan, R. Bindlish, P. O’Neill, T. Jackson, E. Njoku, S. Dunbar, J. Chaubell, J. Piepmeier, S. Yueh, D. Entekhabi, A. Colliander, F. Chen, M. Cosh, T. Caldwell, J. Walker, A. Berg, H. McNairn, M. Thibeault, J. Martínez-Fernández, F. Uldall, M. Seyfried, D. Bosch, P. Starks, C. H. Collins, J. Prueger, R. van der Velde, J. Asanuma, M. Palecki, E. Small, M. Zreda, J. Calvet, W. Crow, and Y. Kerr. Development and assessment of the SMAP enhanced passive soil moisture product. Remote Sensing of Environment, 204:931-941, 2018.

J. Chaubell. SMAP algorithm theoretical basis document: SMAP L1B enhancement radiometer brightness temperature data product. Jet Propulsion Laboratory, 2016.

N. S. Chauhan. Soil moisture estimation under a vegetation cover: Combined active passive microwave remote sensing approach. International Journal of Remote Sensing, 18(5):10791097, 1997.

F. Chen, W. T. Crow, R. Bindlish, A. Colliander, M. S. Burgin, J. Asanuma, and K. Aida. 
Global-scale evaluation of smap, smos and ascat soil moisture products using triple collocation. Remote Sensing of Environment, 214:1 - 13, 2018.

A. Colliander, J. B. Fisher, G. Halverson, O. Merlin, S. Misra, R. Bindlish, T. J. Jackson, and S. Yueh. Spatial downscaling of SMAP soil moisture using MODIS land surface temperature and NDVI during SMAPVEX15. IEEE Geoscience and Remote Sensing Letters, 14(11): 2107-2111, 2017.

C. Corradini. Soil moisture in the development of hydrological processes and its determination at different spatial scales. Journal of Hydrology, 516:1 - 5, 2014.

R. Cragoa and W. Brutsaert. Daytime evaporation and the self-preservation of the evaporative fraction and the bowen ratio. Journal of Hydrology, 178(1-4):241-255, 1996.

N. N. Das, D. Entekhabi, and E. G. Njoku. An algorithm for merging SMAP radiometer and radar data for high-resolution soil-moisture retrieval. IEEE Transactions on Geoscience and Remote Sensing, 49(5):1504-1512, 2011.

N. N. Das, D. Entekhabi, E. G. Njoku, J. J. C. Shi, J. T. Johnson, and A. Colliander. Tests of the SMAP combined radar and radiometer algorithm using airborne field campaign observations and simulated data. IEEE Transactions on Geoscience and Remote Sensing, 52(4):2018-2028, 2014.

N. Djamai, R. Magagi, K. Goita, O. Merlin, Y. Kerr, and A. Walker. Disaggregation of SMOS soil moisture over the Canadian Prairies. Remote Sensing of Environment, 170:255-268, 2015.

D. Entekhabi, T. J. Jackson, E. Njoku, P. O’Neill, and J. Entin. Soil Moisture Active/Passive (SMAP) Mission concept. volume 7085, 2008.

D. Entekhabi, E. G. Njoku, P. E. O’Neill, K. H. Kellogg, W. T. Crow, W. N. Edelstein, J. K. Entin, S. D. Goodman, T. J. Jackson, J. Johnson, J. Kimball, J. R. Piepmeier, R. D. Koster, N. Martin, K. C. McDonald, M. Moghaddam, S. Moran, R. Reichle, J. C. Shi, M. W. Spencer, 
S. W. Thurman, T. Leung, and J. Van Zyl. The Soil Moisture Active Passive (SMAP) Mission. Proceedings of the IEEE, 98(5):704-716, 2010.

B. Fang, V. Lakshmi, R. Bindlish, T. J. Jackson, M. Cosh, and J. Basara. Passive microwave soil moisture downscaling using vegetation index and skin surface temperature. Vadose Zone Journal, 12(3), 2013.

Y. Gao, J. P. Walker, M. Allahmoradi, A. Monerris, R. Dongryeol, and T. J. Jackson. Optical sensing of vegetation water content: A synthesis study. IEEE Journal of Selected Topics in Applied Earth Observations and Remote Sensing, 8(4):1456-1464, 2015.

A. I. Gevaert, R. M. Parinussa, L. J. Renzullo, A. I. J. M. van Dijk, and R. A. M. de Jeu. Spatio-temporal evaluation of resolution enhancement for passive microwave soil moisture and vegetation optical depth. International Journal of Applied Earth Observation and Geoinformation, 2015.

R. R. Gillies and T. N. Carlson. Thermal remote sensing of surface soil water content with partial vegetation cover for incorporation into climate models. Journal of Applied Meteorology, 34 (4):745-756, 1995.

J. P. Grant, K. Saleh-Contell, J. P. Wigneron, M. Guglielmetti, Y. H. Kerr, M. Schwank, N. Skou, and A. A. V. de Griend. Calibration of the L-MEB model over a coniferous and a deciduous forest. IEEE Transactions on Geoscience and Remote Sensing, 46(3):808-818, 2008.

T. J. Jackson. Iii. measuring surface soil moisture using passive microwave remote sensing. Hydrological Processes, 7(2):139-152, 1993.

E. Jacquette, Y. Kerr, A. A. Bitar, F. Cabot, A. Mialon, P. Richaume, A. Quesney, and L. Berthon. CATDS SMOS L3 soil moisture retrieval processor, algorithm theoretical baseline document (ATBD), 2013. 
Y. Kerr, J. Wigneron, A. Al Bitar, A. Mialon, and P. Srivastava. Soil moisture from space: Techniques and limitations. Satellite Soil Moisture Retrieval: Techniques and Applications, page 1, 2016.

R. D. Koster, P. A. Dirmeyer, Z. Guo, G. Bonan, E. Chan, P. Cox, C. T. Gordon, S. Kanae, E. Kowalczyk, D. Lawrence, P. Liu, C.-H. Lu, S. Malyshev, B. McAvaney, K. Mitchell, D. Mocko, T. Oki, K. Oleson, A. Pitman, Y. C. Sud, C. M. Taylor, D. Verseghy, R. Vasic, Y. Xue, and T. Yamada. Regions of strong coupling between soil moisture and precipitation. Science, 305(5687):1138-1140, 2004.

R. D. Koster, S. P., P. M., T. J. Yamada, G. Balsamo, A. A. Berg, M. Boisserie, P. A. Dirmeyer, F. Doblas-Reyes, G. Drewitt, C. T. Gordon, Z. Guo, J. . Jeong, D. M. Lawrence, W. . Lee, Z. Li, L. Luo, S. Malyshev, W. J. Merryfield, S. I. Seneviratne, T. Stanelle, B. J., J. M. v. d. H., F. Vitart, and E. F. Wood. Contribution of land surface initialization to subseasonal forecast skill: First results from a multi-model experiment. Geophysical Research Letters, 37 (2), 2010.

C. Li, H. Lu, K. Yang, M. Han, J. S. Wright, Y. Chen, L. Yu, S. Xu, X. Huang, and W. Gong. The evaluation of SMAP enhanced soil moisture products using high-resolution model simulations and in-situ observations on the tibetan plateau. Remote Sensing, 10(4), 2018. ISSN 2072-4292.

J. G. Liu. Smoothing filter-based intensity modulation: A spectral preserve image fusion technique for improving spatial details. International Journal of Remote Sensing, 21(18):3461$3472,2000$.

D. Long, L. Bai, L. Yan, C. Zhang, W. Yang, H. Lei, J. Quan, X. Meng, and C. Shi. Generation of spatially complete and daily continuous surface soil moisture of high spatial resolution. Remote Sensing of Environment, 233:111364, 2019. ISSN 0034-4257. doi: https://doi.org/ 
10.1016/j.rse.2019.111364. URL http://www.sciencedirect.com/science/article/pii/ S0034425719303839.

D. G. Long. Reconstruction and resolution enhancement techniques for microwave sensors. 2003.

D. G. Long and D. L. Daum. Spatial resolution enhancement of SSM/I data. IEEE Transactions on Geoscience and Remote Sensing, 36(2):407-417, 1998.

O. Merlin, A. Chehbouni, Y. H. Kerr, and D. C. Goodrich. A downscaling method for distributing surface soil moisture within a microwave pixel: Application to the monsoon '90 data. Remote Sensing of Environment, 101(3):379-389, 2006.

O. Merlin, A. Chehbouni, J. P. Walker, R. Panciera, and Y. H. Kerr. A simple method to disaggregate passive microwave-based soil moisture. IEEE Transactions on Geoscience and Remote Sensing, 46(3):786-796, 2008a.

O. Merlin, J. P. Walker, A. Chehbouni, and Y. Kerr. Towards deterministic downscaling of SMOS soil moisture using MODIS derived soil evaporative efficiency. Remote Sensing of Environment, 112(10):3935-3946, 2008b.

O. Merlin, C. Rudiger, A. Al Bitar, P. Richaume, J. P. Walker, and Y. H. Kerr. Disaggregation of SMOS soil moisture in southeastern Australia. IEEE Transactions on Geoscience and Remote Sensing, 50(5):1556-1571, 2012.

O. Merlin, M. J. Escorihuela, M. A. Mayoral, O. Hagolle, A. Al Bitar, and Y. Kerr. Selfcalibrated evaporation-based disaggregation of SMOS soil moisture: An evaluation study at $3 \mathrm{~km}$ and $100 \mathrm{~m}$ resolution in Catalunya, Spain. Remote Sensing of Environment, 130(0): 25-38, 2013.

O. Merlin, Y. Malbéteau, Y. Notfi, S. Bacon, S. Khabba, and L. Jarlan. Performance metrics for 
soil moisture downscaling methods: Application to dispatch data in central morocco. Remote Sensing, 7(4):3783-3807, 2015.

V. Mishra, W. L. Ellenburg, R. E. Griffin, J. R. Mecikalski, J. F. Cruise, C. R. Hain, and M. C. Anderson. An initial assessment of a SMAP soil moisture disaggregation scheme using TIR surface evaporation data over the continental United States. International Journal of Applied Earth Observation and Geoinformation, 68:92 - 104, 2018. ISSN 0303-2434.

B. Molero, O. Merlin, Y. Malbéteau, A. Al Bitar, F. Cabot, V. Stefan, Y. Kerr, S. Bacon, M. H. Cosh, R. Bindlish, and T. J. Jackson. SMOS disaggregated soil moisture product at $1 \mathrm{~km}$ resolution: Processor overview and first validation results. Remote Sensing of Environment, 180:361-376, 2016.

M. S. Moran, T. R. Clarke, Y. Inoue, and A. Vidal. Estimating crop water deficit using the relation between surface-air temperature and spectral vegetation index. Remote Sensing of Environment, 49(3):246-263, 1994.

P. O'Neill, D. Entekhabi, E. Njoku, and K. Kellogg. The NASA Soil Moisture Active Passive (SMAP) mission: Overview. In IEEE International Geoscience and Remote Sensing Symposium (IGARSS), pages 3236-3239, 2010.

M. Owe, R. de Jeu, and J. Walker. A methodology for surface soil moisture and vegetation optical depth retrieval using the microwave polarization difference index. 39:1643 - 1654, 09 2001.

M. Owe, R. de Jeu, and T. Holmes. Multisensor historical climatology of satellite-derived global land surface moisture. Journal of Geophysical Research: Earth Surface, 113(F1), 2008.

R. Panciera, J. P. Walker, J. D. Kalma, E. J. Kim, J. M. Hacker, O. Merlin, M. Berger, and N. Skou. The NAFE'05/CoSMOS data set: Toward SMOS soil moisture retrieval, downscal- 
ing, and assimilation. IEEE Transactions on Geoscience and Remote Sensing, 46(3):736-745, 2008.

R. Panciera, J. P. Walker, J. D. Kalma, E. J. Kim, K. Saleh, and J.-P. Wigneron. Evaluation of the SMOS L-MEB passive microwave soil moisture retrieval algorithm. Remote Sensing of Environment, 113(2):435-444, 2009.

J. Peng, J. Niesel, and A. Loew. Evaluation of soil moisture downscaling using a simple thermalbased proxy - the REMEDHUS network (Spain) example. Hydrology and Earth System Sciences, 19(12):4765-4782, 2015.

J. Peng, A. Loew, Z. Shiqiang, W. Jie, and J. Niesel. Spatial downscaling of satellite soil moisture data using a vegetation temperature condition index. IEEE Transactions on Geoscience and Remote Sensing, 54(1):558-566, 2016.

J. Peng, A. Loew, O. Merlin, and N. E. C. Verhoest. A review of spatial downscaling of satellite remotely sensed soil moisture. Reviews of Geophysics, 2017.

G. P. Petropoulos, G. Ireland, and B. Barrett. Surface soil moisture retrievals from remote sensing: Current status, products \& future trends. Physics and Chemistry of the Earth, Parts $A / B / C,(0), 2015$.

M. Piles, D. Entekhabi, and A. Camps. A change detection algorithm for retrieving highresolution soil moisture from SMAP radar and radiometer observations. IEEE Transactions on Geoscience and Remote Sensing, 47(12):4125-4131, 2009.

M. Piles, A. Camps, M. Vall-llossera, I. Corbella, R. Panciera, C. Rudiger, Y. H. Kerr, and J. Walker. Downscaling SMOS-derived soil moisture using MODIS visible/infrared data. IEEE Transactions on Geoscience and Remote Sensing, 49(9):3156-3166, 2011.

M. Piles, M. Vall-llossera, L. Laguna, and A. Camps. A downscaling approach to combine SMOS multi-angular and full-polarimetric observations with MODIS VIS/IR data into high resolu- 
tion soil moisture maps. In IEEE International Geoscience and Remote Sensing Symposium (IGARSS), pages 1247-1250, 22-27 July 2012. ISBN 2153-6996.

M. Piles, M. Vall-llossera, A. Camps, N. Sánchez, J. Martínez-Fernández, J. Martínez, V. González-Gambau, and R. Riera. On the synergy of SMOS and Terra/Aqua MODIS: High resolution soil moisture maps in near real-time. In IEEE International Geoscience and Remote Sensing Symposium (IGARSS), pages 3423-3426, 21-26 July 2013. ISBN 2153-6996.

M. Piles, G. P. Petropoulos, N. Sánchez, n. González-Zamora, and G. Ireland. Towards improved spatio-temporal resolution soil moisture retrievals from the synergy of SMOS and MSG SEVIRI spaceborne observations. Remote Sensing of Environment, 180:403-417, 2016.

G. A. Poe. Optimum interpolation of imaging microwave radiometer data. IEEE Transactions on geoscience and remote sensing, 28(5):800-810, 1990.

J. W. Rouse, R. Haas, J. Schell, and D. Deering. Monitoring vegetation systems in the great plains with erts. 1974 .

S. Sabaghy, J. P. Walker, L. J. Renzullo, and T. J. Jackson. Spatially enhanced passive microwave derived soil moisture: Capabilities and opportunities. Remote Sensing of Environment, 209:551 - 580, 2018.

E. Santi. An application of the SFIM technique to enhance the spatial resolution of spaceborne microwave radiometers. International Journal of Remote Sensing, 31(9):2419-2428, 2010.

S. I. Seneviratne, T. Corti, E. L. Davin, M. Hirschi, E. B. Jaeger, I. Lehner, B. Orlowsky, and A. J. Teuling. Investigating soil moisture-climate interactions in a changing climate: A review. Earth-Science Reviews, 99(3-4):125-161, 2010.

A. B. Smith, J. P. Walker, A. W. Western, R. I. Young, K. M. Ellett, R. C. Pipunic, R. B. Grayson, L. Siriwidena, F. H. S. Chiew, and H. Richter. The Murrumbidgee soil moisture monitoring network data set. Water Resources Research, 48(W07701):6pp., 2012. 
R. van der Velde, M. S. Salama, M. D. van Helvoirt, Z. Su, and Y. Ma. Decomposition of uncertainties between coarse MM5-Noah-simulated and fine ASAR-retrieved soil moisture over Central Tibet. Journal of Hydrometeorology, 13(6):1925-1938, 2012.

P.-X. Wang, X.-W. Li, J.-Y. Gong, and C. Song. Vegetation temperature condition index and its application for drought monitoring. In IEEE International Geoscience and Remote Sensing Symposium (IGARSS), volume 1, pages 141-143, 2001.

J. P. Wigneron, Y. Kerr, P. Waldteufel, K. Saleh, M. J. Escorihuela, P. Richaume, P. Ferrazzoli, P. de Rosnay, R. Gurney, J. C. Calvet, J. P. Grant, M. Guglielmetti, B. Hornbuckle, C. Mätzler, T. Pellarin, and M. Schwank. L-band microwave emission of the biosphere (LMEB) model: Description and calibration against experimental data sets over crop fields. Remote Sensing of Environment, 107(4):639-655, 2007.

X. Wu, J. P. Walker, N. N. Das, R. Panciera, and C. Rüdiger. Evaluation of the SMAP brightness temperature downscaling algorithm using active-passive microwave observations. Remote Sensing of Environment, 155(0):210-221, 2014.

X. Wu, J. P. Walker, C. Rudiger, R. Panciera, and D. A. Gray. Simulation of the SMAP data stream from SMAPEx field campaigns in Australia. IEEE Transactions on Geoscience and Remote Sensing, 53(4):1921-1934, 2015.

X. Wu, J. P. Walker, C. Rüdiger, R. Panciera, and Y. Gao. Intercomparison of alternate soil moisture downscaling algorithms using active-passive microwave observations. IEEE Geoscience and Remote Sensing Letters, PP(99):1-5, 2016.

N. Ye, J. P. Walker, and C. Rüdiger. A cumulative distribution function method for normalizing variable-angle microwave observations. IEEE Transactions on Geoscience and Remote Sensing, 53(7):3906-3916, 2015.

N. Ye, J. P. Walker, X. Wu, R. d. Jeu, D. Entekhabi, Y. Gao, T. J. Jackson, F. Jonard, E. Kim, 
O. Merlin, V. Pauwels, L. Renzullo, C. Rüdiger, S. Sabaghy, C. v. H. e, S. H. Yueh, and L. Z. a. The soil moisture active passive experiments: Towards calibration and validation of the SMAP mission. IEEE Transactions on Geoscience and Remote Sensing, in review.

M. S. Yee, J. P. Walker, A. Monerris, C. Rüdiger, and T. J. Jackson. On the identification of representative in situ soil moisture monitoring stations for the validation of SMAP soil moisture products in Australia. Journal of Hydrology, 537:367 - 381, 2016.

X. Zhan, P. R. Houser, J. P. Walker, and W. T. Crow. A method for retrieving high-resolution surface soil moisture from hydros l-band radiometer and radar observations. IEEE Transactions on Geoscience and Remote Sensing, 44(6):1534-1544, 2006.

W. Zhao and A. Li. A downscaling method for improving the spatial resolution of AMSR-E derived soil moisture product based on MSG-SEVIRI data. Remote Sensing, 5(12):6790, 2013. 